\title{
Comprehensive genomic characterization of NAC transcription factor family and their response to salt and drought stress in peanut
}

\author{
Cuiling Yuan ${ }^{\dagger}$, Chunjuan $\mathrm{Li}^{\dagger}$, Xiaodong Lu ${ }^{\dagger}$, Xiaobo Zhao, Caixia Yan, Juan Wang, Quanxi Sun ${ }^{*}$ (D) and Shihua Shan*
}

\begin{abstract}
Background: Peanut is one of the most important oil crop species worldwide. NAC transcription factor (TF) genes play important roles in the salt and drought stress responses of plants by activating or repressing target gene expression. However, little is known about NAC genes in peanut.

Results: We performed a genome-wide characterization of NAC genes from the diploid wild peanut species Arachis duranensis and Arachis ipaensis, which included analyses of chromosomal locations, gene structures, conserved motifs, expression patterns, and cis-acting elements within their promoter regions. In total, 81 and 79 NAC genes were identified from A. duranensis and A. ipaensis genomes. Phylogenetic analysis of peanut NACs along with their Arabidopsis and rice counterparts categorized these proteins into 18 distinct subgroups. Fifty-one orthologous gene pairs were identified, and 46 orthologues were found to be highly syntenic on the chromosomes of both $A$. duranensis and A. ipaensis. Comparative RNA sequencing (RNA-seq)-based analysis revealed that the expression of 43 NAC genes was up- or downregulated under salt stress and under drought stress. Among these genes, the expression of 17 genes in cultivated peanut (Arachis hypogaea) was up- or downregulated under both stresses. Moreover, quantitative reverse transcription PCR (RT-qPCR)-based analysis revealed that the expression of most of the randomly selected NAC genes tended to be consistent with the comparative RNA-seq results.
\end{abstract}

Conclusion: Our results facilitated the functional characterization of peanut NAC genes, and the genes involved in salt and drought stress responses identified in this study could be potential genes for peanut improvement.

Keywords: Peanut, NAC gene family, Genome-wide characterization, RNA-seq, RT-qPCR, Salt stress, Drought stress

\section{Background}

Cultivated peanut (Arachis hypogaea) is an important economic oil crop species worldwide and used to provide vegetable oil and proteins for human nutrition [1]. During the growth period of peanut plants, their yield is adversely affected by several environmental factors, such

\footnotetext{
* Correspondence: squanxi@163.com; shansh1971@163.com

${ }^{+}$Cuiling Yuan, Chunjuan Li and Xiaodong Lu contributed equally to this work.

Shandong Peanut Research Institute, Qingdao 266100, China
}

as salt and drought stresses, which prevent plants from realizing their full genetic potential [2]. Screening stressresistant varieties is an important guarantee for achieving targets crop yields [3]. and the identification and utilization of resistant genes is fundamental for the production of new varieties. Transcription factors (TFs), which play roles in activating or repressing gene expression by binding to specific cis-acting elements within the promoters of target functional genes, regulate many biological processes $[4,5]$. As members of one of the largest

(c) The Author(s). 2020 Open Access This article is licensed under a Creative Commons Attribution 4.0 International License, which permits use, sharing, adaptation, distribution and reproduction in any medium or format, as long as you give appropriate credit to the original author(s) and the source, provide a link to the Creative Commons licence, and indicate if changes were made. The images or other third party material in this article are included in the article's Creative Commons licence, unless indicated otherwise in a credit line to the material. If material is not included in the article's Creative Commons licence and your intended use is not permitted by statutory regulation or exceeds the permitted use, you will need to obtain permission directly from the copyright holder. To view a copy of this licence, visit http://creativecommons.org/licenses/by/4.0/ The Creative Commons Public Domain Dedication waiver (http://creativecommons.org/publicdomain/zero/1.0/) applies to the data made available in this article, unless otherwise stated in a credit line to the data. 
plant-specific TF families, NAC [no apical meristem (NAM), Arabidopsis thaliana transcription activation factor (ATAF1/2) and cup-shaped cotyledon (CUC2)] proteins have been shown to regulate several biological processes, including responses to salt and drought stresses [6-8]. Remarkably, NAC TFs are considered to be very important for plant adaptations to land [9]. NAC proteins typically have a conserved NAM domain at the $\mathrm{N}$-terminus and a highly variable domain at the $\mathrm{C}$ terminus, the latter of which is related to specific biological functions. NAC family genes have been studied extensively in a variety of plant species, including gymnosperms and embryophytes [10-19]. However, until recently, comprehensive analyses of peanut NAC family genes and their response patterns to salt and drought stresses have been limited.

Increasing evidences have indicated that NAC proteins are involved in plant biotic and abiotic responses. For example, the poplar NAC13 gene plays a vital role in the salt stress response [20]. Over-expression of a wheat NAC (TaNACL-D1) enhances resistance to Fusarium head blight disease [21], TaNAC30 negatively regulates the resistance of wheat to stripe rust [22], and TaNAC29 can provide salt stress tolerance by enhancing the antioxidant systems [23]. Over-expression of TsNAC1 from the halophyte Thellungiella halophila was shown to improve abiotic stress resistance, especially salt stress tolerance [24]. SINAC35 from Solanum lycopersicum can promote root growth and development under salt and drought stresses [25], and rice ONACO33 is induced by drought and can provide strong resistance to both salt and drought stresses in transgenic plants [26]. In peanut, NAC TFs are known to be involved in responses to abiotic stresses. For example, AhNAC2 and AhNAC3 can improve salt and drought tolerance in transgenic Arabidopsis and tobacco [27, 28], and AhNAC4 confers enhanced drought tolerance to transgenic tobacco [29]. In addition, over-expression of the MuNAC4 transgene from horsegram was shown to confer enhanced drought tolerance to transgenic peanut [30].

The genomes of allotetraploid A. hypogaea (AABB) and its two wild diploid ancestors Arachis duranensis (AA) and Arachis ipaensis (BB) were recently sequenced $[1,31-35]$. The $A$ and $B$ genomes of the two diploid peanut species are similar to the A and B sub-genomes of cultivated peanut and could be used to identify candidate resistance genes $[32,35]$. The availability of genomic information provides opportunities to perform genome-wide analyses of NAC genes and to explore the potential genes involved in peanut biotic and abiotic responses. With the decreasing cost of RNA sequencing (RNA-seq), transcriptome sequencing has become a powerful high-throughput sensitive technique for the analyses of differentially expressed genes. Several peanut
RNA-seq datasets containing information on different tissues or responses to different treatments have been published [36-39]. For example, RNA-seq data generated from 22 different tissues and from the development stage of the diploid peanut species $A$. duranensis and $A$. ipaensis have made it convenient to analyse peanut NAC homologue expression profiles [36]. Differential gene expression in response to salt and drought stress has also been analysed, which can help in the identification of NAC genes involved in salt and drought responses [37, 39].

In this paper, we present the results of a genome-wide identification and characterization of NAC genes from wild peanut genomes and their orthologous genes in response to salt and drought stresses in cultivated peanut. We analysed their phylogenetic relationships, structural characteristics, chromosomal locations and gene orthologous gene pairs. We also determined their expression characteristics in different tissues and in response to salt and drought stresses on the basis of RNA-seq data [36, 37, 39]. Seventeen genes were identified as being involved in the response to both salt and drought stresses in cultivated peanut, and these results were confirmed by quantitative reverse transcription PCR (RT-qPCR). The objectives of this study were to provide a theoretical basis for further functional analysis of NAC proteins in peanut and to explore orthologous NAC genes involved in the response to salt and/or drought stresses in cultivated peanut.

\section{Results}

Identification of NAC proteins from $A$. duranensis and $A$. ipaensis

In total, 81 and 79 NAC genes (Table 1, Additional files 1 and 2) were identified from the diploids $A$. duranensis $(\sim 1.25 \mathrm{~Gb})$ and A. ipaensis( $1.56 \mathrm{~Gb})$, respectively, which were less than the totals identified in Arabidopsis (105) [40] and rice (141) [41]. However, 164 NAC proteins (Additional files 3 and 4) were identified in the cultivated allotetraploid A. hypogaea $(\sim 2.54 \mathrm{~Gb})$. The number was close to the sum of gene numbers from $A$. duranensis and A. ipaensis. The density of NAC genes in A. duranensis $(0.07 / \mathrm{Mb})$ was greater than that $(0.05 / \mathrm{Mb})$ in A. ipaensis. The density of NAC genes in A. hypogaea was $0.06 / \mathrm{Mb}$, which was approximately the average number between $A$. duranensis and $A$. ipaensis.

Owing to the lack of a designated standard annotation for NAC genes in Arachis, we named these genes AdNAC1-AdNAC81 and AiNAC1-AiNAC79. The NAC genes identified in A.duranensis and A.ipaensis encoded proteins ranging from 95 to 681 amino acid (aa) residues in length, with an average of 345 aa, and the molecular weights (MWs) varied from $11 \mathrm{kDa}$ to $77.4 \mathrm{kDa}$. The isoelectric points (pIs) of the predicted proteins ranged 
Table 1 NAC TF gene family members in wild Arachis

\begin{tabular}{|c|c|c|c|c|c|c|c|c|c|}
\hline $\begin{array}{l}\text { Gene } \\
\text { symbol }\end{array}$ & $\begin{array}{l}\text { Gene model } \\
\text { name }\end{array}$ & Gene location & $\begin{array}{l}\text { Length } \\
\text { (aa) }\end{array}$ & $\begin{array}{l}\mathrm{MW} \\
(\mathrm{kDa})\end{array}$ & $\begin{array}{l}\text { Theoretical } \\
\mathrm{pl}\end{array}$ & $\begin{array}{l}\text { Putative } \\
\text { Arabidopsis } \\
\text { orthologues }\end{array}$ & $\begin{array}{l}\text { Closest } \\
\text { genes }\end{array}$ & $\begin{array}{l}\mathrm{E}- \\
\text { value }\end{array}$ & $\begin{array}{l}\text { Othologous genes } \\
\text { with known function }\end{array}$ \\
\hline AdNAC1 & Aradu.08GFU.1 & $\begin{array}{l}\text { Chr7: } \\
\text { 4217194..4220440 }\end{array}$ & 367 & 42.7 & 6.19 & ANAC42 & & $4 e-85$ & \\
\hline AdNAC2 & Aradu.08TAH.1 & $\begin{array}{l}\text { Chr10: } \\
\text { 5997735..5999148 }\end{array}$ & 229 & 26.7 & 5.56 & ANAC104/XND1 & & $2 e-90$ & \\
\hline AdNAC3 & Aradu.0MJ0X.1 & $\begin{array}{l}\text { Chr3: } \\
\text { 11724103..11725980 }\end{array}$ & 384 & 44.0 & 7.45 & ANAC70 & & $\begin{array}{l}3 e- \\
157\end{array}$ & \\
\hline AdNAC4 & Aradu.13D06.1 & $\begin{array}{l}\text { Chr1: } \\
\text { 100229649..100231496 }\end{array}$ & 396 & 45.3 & 6.86 & ANAC35 & & $\begin{array}{l}1 e- \\
119\end{array}$ & \\
\hline AdNAC5 & Aradu.15JI0.1 & $\begin{array}{l}\text { Chr8: } \\
\text { 28519479..28520527 }\end{array}$ & 150 & 16.7 & 8.69 & & ANAC90 & $1 e-28$ & \\
\hline AdNAC6 & Aradu.15QQT.1 & $\begin{array}{l}\text { Chr1: } \\
17654260.17657374\end{array}$ & 135 & 32.8 & 9.35 & & ANAC14 & $3 e-28$ & \\
\hline AdNAC7 & Aradu.1AJ4F.1 & $\begin{array}{l}\text { Chr7: } \\
46474022.46478416\end{array}$ & 350 & 40.4 & 6.93 & ANAC33 & & $\begin{array}{l}5 e- \\
123\end{array}$ & \\
\hline AdNAC8 & Aradu.215DG.1 & $\begin{array}{l}\text { Chr10: } \\
\text { 2443477..2446668 }\end{array}$ & 322 & 36.8 & 8.14 & ANAC73 & & $\begin{array}{l}1 e- \\
114\end{array}$ & \\
\hline AdNAC9 & Aradu.22647.1 & $\begin{array}{l}\text { Chr10: } \\
\text { 106757870..106759333 }\end{array}$ & 274 & 31.6 & 6.00 & ANAC87 & & $\begin{array}{l}4 \mathrm{e}^{-} \\
100\end{array}$ & \\
\hline AdNAC10 & Aradu.30S8W.1 & $\begin{array}{l}\text { Chr1: } \\
42645387 . .42650347\end{array}$ & 288 & 33.6 & 6.94 & ANAC7NND4 & & $\begin{array}{l}2 e^{-} \\
103\end{array}$ & \\
\hline AdNAC11 & Aradu.3R7A3.1 & $\begin{array}{l}\text { Chr6: } \\
\text { 99554879..99559186 }\end{array}$ & 481 & 53.7 & 5.05 & ANAC44 & & $3 e-92$ & \\
\hline AdNAC12 & Aradu.46U1T.1 & $\begin{array}{l}\text { Chr6: } \\
\text { 8759633..8760991 }\end{array}$ & 251 & 28.0 & 6.37 & & $\begin{array}{l}\text { ANAC28/ } \\
\text { TIP }\end{array}$ & $5 e-13$ & \\
\hline AdNAC13 & Aradu.47JQU.1 & $\begin{array}{l}\text { Chr8: } \\
\text { 49202066..49203551 }\end{array}$ & 321 & 36.3 & 8.99 & ANAC100 & & $\begin{array}{l}3 e- \\
124\end{array}$ & \\
\hline AdNAC14 & Aradu.4RJOE.1 & $\begin{array}{l}\text { Chr6: } \\
\text { 90892652..90894340 }\end{array}$ & 355 & 40.2 & 9.35 & ANAC47 & & $\begin{array}{l}7 e- \\
104\end{array}$ & \\
\hline AdNAC15 & Aradu.58D1A.1 & $\begin{array}{l}\text { Chr8: } \\
\text { 48242228..48244188 }\end{array}$ & 193 & 22.8 & 10.13 & & ANAC83 & $4 e-63$ & \\
\hline AdNAC16 & Aradu.5D5JN.1 & $\begin{array}{l}\text { Chr10: } \\
\text { 66508689..66512014 }\end{array}$ & 592 & 67.0 & 5.52 & ANAC9 & & $1 e-94$ & \\
\hline AdNAC17 & Aradu.60 U13.1 & $\begin{array}{l}\text { Chr10: } \\
95255502 . .95259031\end{array}$ & 374 & 41.6 & 8.64 & ANAC38 & & $\begin{array}{l}3 e- \\
111\end{array}$ & \\
\hline AdNAC18 & Aradu.66XRP.1 & $\begin{array}{l}\text { Chr3: } \\
\text { 118432883...118434275 }\end{array}$ & 318 & 34.9 & 7.79 & ANAC25 & & $\begin{array}{l}1 e- \\
107\end{array}$ & \\
\hline AdNAC19 & Aradu.6H4PP.1 & $\begin{array}{l}\text { Chr10: } \\
\text { 84012608..84013897 }\end{array}$ & 230 & 26.1 & 5.23 & & $\begin{array}{l}\text { ANAC104/ } \\
\text { XND1 }\end{array}$ & & \\
\hline AdNAC20 & Aradu.79PL2.1 & $\begin{array}{l}\text { Chr3: } \\
\text { 106298423..106299692 }\end{array}$ & 211 & 23.6 & 9.45 & ANAC41 & & $4 e-64$ & \\
\hline AdNAC21 & Aradu.7NI41.1 & $\begin{array}{l}\text { Chr3: } \\
\text { 20188210..20192587 }\end{array}$ & 286 & 32.6 & 8.19 & ANAC73 & & $\begin{array}{l}2 e- \\
110\end{array}$ & \\
\hline AdNAC22 & Aradu.7X5EV.1 & $\begin{array}{l}\text { Chr8: } \\
\text { 36760639..36761970 }\end{array}$ & 328 & 36.3 & 8.67 & ANAC2 & & $\begin{array}{l}9 e- \\
121\end{array}$ & \\
\hline AdNAC23 & Aradu.ZT2TE.1 & $\begin{array}{l}\text { Chr5: } \\
\text { 108980829..108983109 }\end{array}$ & 341 & 39.3 & 6.30 & ANAC7NND5 & & $\begin{array}{l}2 e^{-} \\
114\end{array}$ & \\
\hline AdNAC24 & Aradu.8Q7DY.1 & $\begin{array}{l}\text { Chr10: } \\
\text { 100727698..100729562 }\end{array}$ & 313 & 36.1 & 8.50 & ANAC94 & & $3 e-87$ & \\
\hline AdNAC25 & Aradu.9FF24.1 & $\begin{array}{l}\text { Chr9: } \\
\text { 104552010..104554828 }\end{array}$ & 583 & 65.2 & 4.72 & ANAC53 & & $2 e-88$ & \\
\hline AdNAC26 & Aradu.9T4H8.1 & $\begin{array}{l}\text { Chr3: } \\
129693427 . .129694223\end{array}$ & 228 & 25.8 & 4.95 & ANAC104/XND1 & & $3 e-77$ & \\
\hline
\end{tabular}


Table 1 NAC TF gene family members in wild Arachis (Continued)

\begin{tabular}{|c|c|c|c|c|c|c|c|c|c|}
\hline $\begin{array}{l}\text { Gene } \\
\text { symbol }\end{array}$ & $\begin{array}{l}\text { Gene model } \\
\text { name }\end{array}$ & Gene location & $\begin{array}{l}\text { Length } \\
\text { (aa) }\end{array}$ & $\begin{array}{l}\mathrm{MW} \\
(\mathrm{kDa})\end{array}$ & $\begin{array}{l}\text { Theoretical } \\
\text { pl }\end{array}$ & $\begin{array}{l}\text { Putative } \\
\text { Arabidopsis } \\
\text { orthologues }\end{array}$ & $\begin{array}{l}\text { Closest } \\
\text { genes }\end{array}$ & $\begin{array}{l}\mathrm{E}- \\
\text { value }\end{array}$ & $\begin{array}{l}\text { Othologous genes } \\
\text { with known function }\end{array}$ \\
\hline AdNAC27 & Aradu.9Y6NH.1 & $\begin{array}{l}\text { Chr3: } \\
\text { 126203898..126205566 }\end{array}$ & 432 & 48.2 & 6.86 & ANAC94 & & $7 e-96$ & \\
\hline AdNAC28 & Aradu.AF9FZ.1 & $\begin{array}{l}\text { Chr3: } \\
11453829 . .11456527\end{array}$ & 373 & 43.2 & 5.89 & ANAC7/NND5 & & $\begin{array}{l}6 e^{-} \\
118\end{array}$ & \\
\hline AdNAC29 & Aradu.B5XXI.1 & $\begin{array}{l}\text { Chr5: } \\
89010001 . .89014271\end{array}$ & 405 & 50.5 & 6.97 & ANAC75 & & $\begin{array}{l}2 e^{-} \\
149\end{array}$ & \\
\hline AdNAC30 & Aradu.BPK98.1 & $\begin{array}{l}\text { Chr2: } \\
5418916 . .5424040\end{array}$ & 463 & 52.5 & 5.81 & & ANAC9 & $2 e-50$ & \\
\hline AdNAC31 & Aradu.BS3JU.1 & $\begin{array}{l}\text { Chr8: } \\
\text { 32409380..32411511 }\end{array}$ & 300 & 34.1 & 8.55 & ANAC73 & & $\begin{array}{l}2 e- \\
116\end{array}$ & \\
\hline AdNAC32 & Aradu.C1Q0A.1 & $\begin{array}{l}\text { Chr8: } \\
\text { 28596303..28598519 }\end{array}$ & 372 & 41.9 & 7.53 & ANAC40/NTL8 & & 4e-99 & \\
\hline AdNAC33 & Aradu.DII8L.1 & $\begin{array}{l}\text { Chr4: } \\
123542703 . .123544293\end{array}$ & 245 & 27.8 & 9.00 & ANAC83 & & $\begin{array}{l}1 e- \\
102\end{array}$ & \\
\hline AdNAC34 & Aradu.DQR3M.1 & $\begin{array}{l}\text { Chr10: } \\
\text { 3280639..3282098 }\end{array}$ & 347 & 39.5 & 6.81 & ANAC25 & & $6 e-96$ & \\
\hline AdNAC35 & Aradu.EP425.1 & $\begin{array}{l}\text { Chr10: } \\
83305166 . .83307784\end{array}$ & 367 & 40.4 & 4.75 & ANAC82 & & $7 e-91$ & \\
\hline AdNAC36 & Aradu.ETZ8K.1 & $\begin{array}{l}\text { Chr5: } \\
\text { 5429577..5431170 }\end{array}$ & 356 & 40.3 & 5.20 & ANAC71 & & $\begin{array}{l}2 e^{-} \\
109\end{array}$ & \\
\hline AdNAC37 & Aradu.F2DT2.1 & $\begin{array}{l}\text { Chr8: } \\
\text { 26149830..26151706 }\end{array}$ & 360 & 41.0 & 5.95 & ANAC25 & & 1e-78 & \\
\hline AdNAC38 & Aradu.F48KW.1 & $\begin{array}{l}\text { Chr9: } \\
118016952 . .118020856\end{array}$ & 557 & 63.0 & 4.58 & ANAC16 & & $\begin{array}{l}1 e^{-} \\
131\end{array}$ & \\
\hline AdNAC39 & Aradu.F6Z4G.1 & $\begin{array}{l}\text { Chr1: } \\
\text { 105899702..105901040 }\end{array}$ & 330 & 37.2 & 8.16 & ANAC100 & & $\begin{array}{l}7 e- \\
139\end{array}$ & \\
\hline AdNAC40 & Aradu.F8VRL.1 & $\begin{array}{l}\text { Chr3: } \\
\text { 30065645..30068198 }\end{array}$ & 382 & 43.0 & 7.69 & ANAC75 & & $\begin{array}{l}2 e^{-} \\
123\end{array}$ & \\
\hline AdNAC41 & Aradu.H2YS3.1 & $\begin{array}{l}\text { Chr6: } \\
113116 . .11132912\end{array}$ & 226 & 26.1 & 7.22 & & ANAC74 & $2 e-61$ & \\
\hline AdNAC42 & Aradu.H5KV7.1 & $\begin{array}{l}\text { Chr10: } \\
\text { 101199649..101202008 }\end{array}$ & 317 & 36.6 & 4.96 & $\begin{array}{l}\text { ANAC79/ANAC80/ } \\
\text { ATNAC4 }\end{array}$ & & $4 e-85$ & \\
\hline AdNAC43 & Aradu.JV7AK.1 & $\begin{array}{l}\text { Chr5: } \\
\text { 103968982..103973619 }\end{array}$ & 451 & 50.9 & 5.21 & ANAC8 & & $\begin{array}{l}4 e^{-} \\
150\end{array}$ & \\
\hline AdNAC44 & Aradu.JZK1S.1 & $\begin{array}{l}\text { Chr7: } \\
\text { 10652666..10652977 }\end{array}$ & 95 & 11.0 & 9.22 & & ANAC14 & $5 e-06$ & \\
\hline AdNAC45 & Aradu.K2UJH.1 & $\begin{array}{l}\text { Chr7: } \\
\text { 28089666..28093564 }\end{array}$ & 681 & 75.4 & 4.57 & ANAC14 & & $7 e-58$ & \\
\hline AdNAC46 & Aradu.KF8UQ.1 & $\begin{array}{l}\text { Chr3: } \\
111110289.1111111452\end{array}$ & 184 & 21.1 & 5.66 & & $\begin{array}{l}\text { ANAC104/ } \\
\text { XND1 }\end{array}$ & $3 e-36$ & \\
\hline AdNAC47 & Aradu.L3QY1.1 & $\begin{array}{l}\text { Chr1: } \\
\text { 27306711..27309985 }\end{array}$ & 331 & 37.2 & 4.82 & ANAC71 & & $2 e-97$ & \\
\hline AdNAC48 & Aradu.L6S7Y.1 & $\begin{array}{l}\text { Chr2: } \\
14425633 . .14431626\end{array}$ & 246 & 27.8 & 5.89 & ANAC74 & & $1 e-81$ & \\
\hline AdNAC49 & Aradu.L8SVN.1 & $\begin{array}{l}\text { Chr3: } \\
\text { 126544444..126545867 }\end{array}$ & 286 & 32.8 & 8.32 & ANAC2 & & $\begin{array}{l}2 e^{-} \\
109\end{array}$ & \\
\hline AdNAC50 & Aradu.LG4RX.1 & $\begin{array}{l}\text { Chr6: } \\
\text { 95430437..95431819 }\end{array}$ & 218 & 25.2 & 9.18 & & ANAC83 & $3 e-21$ & \\
\hline AdNAC51 & Aradu.LZOD8.1 & $\begin{array}{l}\text { Chr7: } \\
\text { 70232857..70235212 }\end{array}$ & 351 & 40.3 & 8.49 & ANAC42 & & $2 e-86$ & \\
\hline AdNAC52 & Aradu.M7213.1 & $\begin{array}{l}\text { Chr5: } \\
11521321 . .11523020\end{array}$ & 324 & 37.4 & 5.38 & ANAC1 & & $\begin{array}{l}2 e^{-} \\
140\end{array}$ & \\
\hline
\end{tabular}


Table 1 NAC TF gene family members in wild Arachis (Continued)

\begin{tabular}{|c|c|c|c|c|c|c|c|c|c|}
\hline $\begin{array}{l}\text { Gene } \\
\text { symbol }\end{array}$ & $\begin{array}{l}\text { Gene model } \\
\text { name }\end{array}$ & Gene location & $\begin{array}{l}\text { Length } \\
\text { (aa) }\end{array}$ & $\begin{array}{l}\text { MW } \\
(\mathrm{kDa})\end{array}$ & $\begin{array}{l}\text { Theoretical } \\
\text { pl }\end{array}$ & $\begin{array}{l}\text { Putative } \\
\text { Arabidopsis } \\
\text { orthologues }\end{array}$ & $\begin{array}{l}\text { Closest } \\
\text { genes }\end{array}$ & $\begin{array}{l}\text { E- } \\
\text { value }\end{array}$ & $\begin{array}{l}\text { Othologous genes } \\
\text { with known function }\end{array}$ \\
\hline AdNAC53 & Aradu.M8PFR.1 & $\begin{array}{l}\text { Chr9: } \\
\text { 104514608..104520535 }\end{array}$ & 425 & 47.9 & 8.63 & ANAC52 & & $1 e-86$ & \\
\hline AdNAC54 & Aradu.M9GL4.1 & $\begin{array}{l}\text { Chr5: } \\
\text { 50856073..50857364 }\end{array}$ & 308 & 35.3 & 7.68 & ANAC2 & & $\begin{array}{l}8 e^{-} \\
118\end{array}$ & \\
\hline AdNAC55 & Aradu.N8F6V.1 & $\begin{array}{l}\text { Chr5: } \\
\text { 82433539..82435658 }\end{array}$ & 363 & 40.2 & 9.35 & ANAC040 & & $3 e-81$ & \\
\hline AdNAC56 & Aradu.N8MU8.1 & $\begin{array}{l}\text { Chr5: } \\
\text { 93368562..93371821 }\end{array}$ & 362 & 41.0 & 7.21 & ANAC58 & & $\begin{array}{l}2 e^{-} \\
125\end{array}$ & \\
\hline AdNAC57 & Aradu.NEU1C.1 & $\begin{array}{l}\text { Chr2: } \\
\text { 5363506..5368149 }\end{array}$ & 255 & 29.6 & 5.41 & & ANAC14 & $3 e-39$ & \\
\hline AdNAC58 & Aradu.R9F07.1 & $\begin{array}{l}\text { Chr2: } \\
4630145 . .4632702\end{array}$ & 463 & 51.1 & 6.05 & ANAC66 & & $\begin{array}{l}1 e^{-} \\
104\end{array}$ & \\
\hline AdNAC59 & Aradu.RP61F.1 & $\begin{array}{l}\text { Chr6: } \\
110760391 . .110763962\end{array}$ & 306 & 34.5 & 5.60 & & ANAC7 & $1 e-19$ & \\
\hline AdNAC60 & Aradu.RRT20.1 & $\begin{array}{l}\text { Chr5: } \\
\text { 13469204..13471956 }\end{array}$ & 394 & 45.6 & 6.98 & ANAC7 & & $\begin{array}{l}3 e- \\
116\end{array}$ & \\
\hline AdNAC61 & Aradu.S13QQ.1 & $\begin{array}{l}\text { Chr6: } \\
\text { 25318703..25322833 }\end{array}$ & 344 & 39.3 & 6.33 & ANAC25 & & $2 e-83$ & \\
\hline AdNAC62 & Aradu.TGA11.1 & $\begin{array}{l}\text { Chr3: } \\
7357966 . .7359851\end{array}$ & 315 & 36.3 & 6.62 & ANAC36 & & $\begin{array}{l}2 e^{-} \\
117\end{array}$ & \\
\hline AdNAC63 & Aradu.TI0Z7.1 & $\begin{array}{l}\text { Chr7: } \\
34924555 . .34930380\end{array}$ & 322 & 36.4 & 7.57 & ANAC1 & & $\begin{array}{l}1 e^{-} \\
124\end{array}$ & \\
\hline AdNAC64 & Aradu.U974Q.1 & $\begin{array}{l}\text { Chr3: } \\
\text { 122754747..122758369 }\end{array}$ & 633 & 71.7 & 6.34 & ANAC28 & & $\begin{array}{l}2 e^{-} \\
141\end{array}$ & \\
\hline AdNAC65 & Aradu.USH95.1 & $\begin{array}{l}\text { Chr8: } \\
\text { 38011875..38013744 }\end{array}$ & 369 & 40.7 & 7.22 & ANAC100 & & $4 e-90$ & \\
\hline AdNAC66 & Aradu.UXN6T.1 & $\begin{array}{l}\text { Chr8: } \\
46083445 . .46085088\end{array}$ & 304 & 35.1 & 6.42 & ANAC032 & & $3 e-96$ & \\
\hline AdNAC67 & Aradu.VUC67.1 & $\begin{array}{l}\text { Chr9: } \\
118496634 . .118500190\end{array}$ & 321 & 37.5 & 6.76 & ANAC7 & & $\begin{array}{l}2 e^{-} \\
113\end{array}$ & \\
\hline AdNAC68 & Aradu.W3GLH.1 & $\begin{array}{l}\text { Chr7: } \\
\text { 15758174..15764123 }\end{array}$ & 679 & 77.4 & 5.43 & ANAC28 & & $\begin{array}{l}8 \mathrm{e}- \\
167\end{array}$ & \\
\hline AdNAC69 & Aradu.WITOW.1 & $\begin{array}{l}\text { Chr7: } \\
44242604 . .44246557\end{array}$ & 346 & 39.5 & 5.05 & ANAC20 & & $2 e-96$ & \\
\hline AdNAC70 & Aradu.WS3DN.1 & $\begin{array}{l}\text { Chr6: } \\
\text { 71790233..71791501 }\end{array}$ & 213 & 24.4 & 5.39 & ANAC90 & & $1 e-45$ & \\
\hline AdNAC71 & Aradu.XE8WZ.1 & $\begin{array}{l}\text { Chr3: } \\
111523591 . .111525548\end{array}$ & 300 & 33.0 & 5.09 & & ANAC103 & $2 e-50$ & \\
\hline AdNAC72 & Aradu.XJF09.1 & $\begin{array}{l}\text { Chr5: } \\
86074509 . .86078409\end{array}$ & 396 & 43.6 & 6.47 & ANAC44 & & $2 e-87$ & \\
\hline AdNAC73 & Aradu.XQ4VP.1 & $\begin{array}{l}\text { Chr5: } \\
\text { 98563335..98567633 }\end{array}$ & 167 & 19.5 & 8.87 & ANAC57 & & $4 e-90$ & \\
\hline AdNAC74 & Aradu.Y1DM8.1 & $\begin{array}{l}\text { Chr6: } \\
\text { 90691784..90693411 }\end{array}$ & 396 & 44.5 & 6.21 & ANAC46 & & $\begin{array}{l}5 e- \\
111\end{array}$ & \\
\hline AdNAC75 & Aradu.Y9JNS.1 & $\begin{array}{l}\text { Chr8: } \\
4371901 . .4373364\end{array}$ & 369 & 41.6 & 7.84 & ANAC100 & & $5 e-75$ & \\
\hline AdNAC76 & Aradu.YFQ3P.1 & $\begin{array}{l}\text { Chr3: } \\
110319904 . .110321231\end{array}$ & 260 & 29.8 & 7.71 & ANAC102 & & $\begin{array}{l}7 e- \\
113\end{array}$ & \\
\hline AdNAC77 & Aradu.YIQ80.1 & $\begin{array}{l}\text { Chr8: } \\
\text { 36879860..36881784 }\end{array}$ & 349 & 39.1 & 8.20 & ANAC19 & & $\begin{array}{l}4 e^{-} \\
120\end{array}$ & $\begin{array}{l}\text { AhNAC4 (HM776131) } \\
\text { [29] }\end{array}$ \\
\hline dNAC78 & Aradu.YXWOZ.1 & $\begin{array}{l}\text { Chr3: } \\
119828022 . .119831252\end{array}$ & 342 & 38.6 & 8.66 & ANAC10/SND3 & & $\begin{array}{l}1 e^{-} \\
120\end{array}$ & \\
\hline
\end{tabular}


Table 1 NAC TF gene family members in wild Arachis (Continued)

\begin{tabular}{|c|c|c|c|c|c|c|c|c|c|}
\hline $\begin{array}{l}\text { Gene } \\
\text { symbol }\end{array}$ & $\begin{array}{l}\text { Gene model } \\
\text { name }\end{array}$ & Gene location & $\begin{array}{l}\text { Length } \\
\text { (aa) }\end{array}$ & $\begin{array}{l}\text { MW } \\
(\mathrm{kDa})\end{array}$ & $\begin{array}{l}\text { Theoretical } \\
\text { pl }\end{array}$ & $\begin{array}{l}\text { Putative } \\
\text { Arabidopsis } \\
\text { orthologues }\end{array}$ & $\begin{array}{l}\text { Closest } \\
\text { genes }\end{array}$ & $\begin{array}{l}\mathrm{E}- \\
\text { value }\end{array}$ & $\begin{array}{l}\text { Othologous genes } \\
\text { with known function }\end{array}$ \\
\hline AdNAC79 & Aradu.Z4K97.1 & $\begin{array}{l}\text { Chr9: } \\
\text { 120442436..120446530 }\end{array}$ & 493 & 55.0 & 5.11 & ANAC8 & & $\begin{array}{l}3 e- \\
127\end{array}$ & \\
\hline AdNAC80 & Aradu.Z5H58.1 & $\begin{array}{l}\text { Chr3: } \\
\text { 25915995..25917258 }\end{array}$ & 335 & 37.7 & 6.61 & ANAC3 & & $\begin{array}{l}3 e- \\
110\end{array}$ & \\
\hline AdNAC81 & Aradu.Z9Y3J.1 & $\begin{array}{l}\text { Chr4: } \\
117994993 . .117996740\end{array}$ & 330 & 38.0 & 5.72 & ANAC100 & & $6 e-89$ & \\
\hline AiNAC1 & Araip.0550R.1 & Chr3:197325..198893 & 330 & 37.5 & 9.04 & ANAC100 & & $\begin{array}{l}3 e- \\
123\end{array}$ & \\
\hline AiNAC2 & Araip.0S3ـ1 & $\begin{array}{l}\text { Chr5: } \\
\text { 139720050..139724356 }\end{array}$ & 358 & 40.3 & 6.40 & ANAC75 & & $\begin{array}{l}1 e^{-} \\
143\end{array}$ & \\
\hline AiNAC3 & Araip.1N7IP.1 & $\begin{array}{l}\text { Chr10: } \\
4025791 . .4028779\end{array}$ & 324 & 36.9 & 8.41 & ANAC73 & & $\begin{array}{l}8 \mathrm{e}- \\
115\end{array}$ & \\
\hline AiNAC4 & Araip.1ZOSD.1 & $\begin{array}{l}\text { Chr3: } \\
\text { 33051241..33054714 }\end{array}$ & 381 & 42.7 & 7.33 & ANAC75 & & $\begin{array}{l}1 e- \\
123\end{array}$ & \\
\hline AiNAC5 & Araip.2BL8E.1 & $\begin{array}{l}\text { Chr8: } \\
\text { 5815169..5817042 }\end{array}$ & 320 & 36.2 & 9.08 & ANAC40 & & $9 e-84$ & \\
\hline AiNAC6 & Araip.2W5R5.1 & $\begin{array}{l}\text { Chr10: } \\
\text { 93270958..93274136 }\end{array}$ & 592 & 67.0 & 5.46 & ANAC14 & & $2 e-91$ & \\
\hline AiNAC7 & Araip.310T2.1 & $\begin{array}{l}\text { Chr7: } \\
118782789.118785019\end{array}$ & 301 & 33.7 & 6.54 & ANAC32 & & $\begin{array}{l}2 e^{-} \\
108\end{array}$ & \\
\hline AiNAC8 & Araip.31EFM.1 & $\begin{array}{l}\text { Chr5: } \\
\text { 142199068..142203628 }\end{array}$ & 410 & 45.4 & 5.76 & ANAC85 & & $2 e-85$ & \\
\hline AiNAC9 & Araip.333QY.1 & $\begin{array}{l}\text { Chr3: } \\
\text { 28574038..28575297 }\end{array}$ & 335 & 37.7 & 6.61 & ANAC19 & & $\begin{array}{l}3 e- \\
109\end{array}$ & $\begin{array}{l}\text { AhNAC3 (EU755022) } \\
\text { [28] }\end{array}$ \\
\hline AiNAC10 & Araip.4A49L.1 & $\begin{array}{l}\text { Chr5: } \\
\text { 144854742..144856564 }\end{array}$ & 285 & 32.5 & 6.97 & ANAC40 & & $9 e-74$ & \\
\hline AiNAC11 & Araip.6Cl1F & $\begin{array}{l}\text { Chr10: } \\
\text { 127061923..127064519 }\end{array}$ & 391 & 45.5 & 5.07 & ANAC79 & & $5 e-73$ & \\
\hline AiNAC12 & Araip.609WS.1 & $\begin{array}{l}\text { Chr5: } \\
\text { 134972759..134976087 }\end{array}$ & 363 & 41.1 & 7.21 & ANAC58 & & $\begin{array}{l}2 e- \\
123\end{array}$ & \\
\hline AiNAC13 & Araip.64GCN.1 & $\begin{array}{l}\text { Chr5: } \\
45189298 . .45190788\end{array}$ & 308 & 35.4 & 7.69 & ANAC25 & & $1 e-82$ & \\
\hline AiNAC14 & Araip.67R8V & $\begin{array}{l}\text { Chr6: } \\
\text { 123068423..123072685 }\end{array}$ & 471 & 52.6 & 5.11 & ANAC44 & & $3 e-93$ & \\
\hline AiNAC15 & Araip.6YOGY & $\begin{array}{l}\text { Chr7: } \\
\text { 4085598..4089132 }\end{array}$ & 280 & 32.7 & 5.49 & ANAC042 & & $2 e-27$ & \\
\hline AiNAC16 & Araip.714GL & $\begin{array}{l}\text { Chr9: } \\
\text { 138000623..138005210 }\end{array}$ & 559 & 63.3 & 4.57 & ANAC016 & & $\begin{array}{l}8 \mathrm{e}- \\
134\end{array}$ & \\
\hline AiNAC17 & Araip.71CS3 & $\begin{array}{l}\text { Chr10: } \\
\text { 107295010..107298155 }\end{array}$ & 367 & 40.4 & 4.72 & ANAC103 & & $6 e-87$ & \\
\hline AiNAC18 & Araip.77ISR & $\begin{array}{l}\text { Chr2: } \\
\text { 17820382..17822891 }\end{array}$ & 257 & 28.9 & 8.49 & ANAC74 & & $1 e-63$ & \\
\hline AiNAC19 & Araip.78PTT & $\begin{array}{l}\text { Chr8: } \\
\text { 24667634..246699998 }\end{array}$ & 366 & 40.4 & 7.22 & ANAC100 & & $8 \mathrm{e}-90$ & \\
\hline AiNAC20 & Araip.79TDF & $\begin{array}{l}\text { Chr7: } \\
\text { 16494343..16499499 }\end{array}$ & 678 & 77.3 & 5.51 & ANAC086 & & $\begin{array}{l}1 e- \\
115\end{array}$ & \\
\hline AiNAC21 & Araip.7L9YW & $\begin{array}{l}\text { Chr5: } \\
110392178 . .110396183\end{array}$ & 497 & 56.8 & 5.05 & ANAC8 & & $\begin{array}{l}6 e- \\
121\end{array}$ & \\
\hline AiNAC22 & Araip.8NR3H & $\begin{array}{l}\text { Chr3: } \\
111878869 . .111880200\end{array}$ & 260 & 29.9 & 7.09 & ANAC032 & & $8 e-98$ & \\
\hline AiNAC23 & Araip.92BTQ & $\begin{array}{l}\text { Chr10: } \\
\text { 108502499..108503880 }\end{array}$ & 213 & 24.3 & 5.25 & & ANAC104 & $3 e-55$ & \\
\hline
\end{tabular}


Table 1 NAC TF gene family members in wild Arachis (Continued)

\begin{tabular}{|c|c|c|c|c|c|c|c|c|c|}
\hline $\begin{array}{l}\text { Gene } \\
\text { symbol }\end{array}$ & $\begin{array}{l}\text { Gene model } \\
\text { name }\end{array}$ & Gene location & $\begin{array}{l}\text { Length } \\
\text { (aa) }\end{array}$ & $\begin{array}{l}\text { MW } \\
(\mathrm{kDa})\end{array}$ & $\begin{array}{l}\text { Theoretical } \\
\text { pl }\end{array}$ & $\begin{array}{l}\text { Putative } \\
\text { Arabidopsis } \\
\text { orthologues }\end{array}$ & $\begin{array}{l}\text { Closest } \\
\text { genes }\end{array}$ & $\begin{array}{l}\text { E- } \\
\text { value }\end{array}$ & $\begin{array}{l}\text { Othologous genes } \\
\text { with known function }\end{array}$ \\
\hline AiNAC24 & Araip.9BR1Z & $\begin{array}{l}\text { Chr3: } \\
112774516 . .112775399\end{array}$ & 202 & 23.2 & 5.19 & & ANAC104 & $3 e-47$ & \\
\hline AiNAC25 & Araip.9MG9F & $\begin{array}{l}\text { Chr3: } \\
\text { 22778530..22786094 }\end{array}$ & 321 & 36.6 & 7.37 & ANAC75 & & $1 e-95$ & \\
\hline AiNAC26 & Araip.9N5S4 & $\begin{array}{l}\text { Chr3: } \\
\text { 14030155..14031366 }\end{array}$ & 338 & 39.0 & 5.91 & ANAC7 & & $\begin{array}{l}4 \mathrm{e}- \\
116\end{array}$ & \\
\hline AiNAC27 & Araip.9W6SR & $\begin{array}{l}\text { Chr3: } \\
\text { 123433544..123436914 }\end{array}$ & 633 & 71.6 & 6.09 & ANAC86 & & $\begin{array}{l}2 \mathrm{e}- \\
113\end{array}$ & \\
\hline AiNAC28 & Araip.A6QWC & $\begin{array}{l}\text { Chr2: } \\
6650205.6654171\end{array}$ & 481 & 54.6 & 5.61 & & ANAC14 & $3 e-51$ & \\
\hline AiNAC29 & Araip.AW74 & $\begin{array}{l}\text { Chr4: } \\
\text { 127912708..127914469 }\end{array}$ & 330 & 38.1 & 5.82 & ANAC100 & & $3 e-88$ & \\
\hline AiNAC30 & Araip.AWFOA & $\begin{array}{l}\text { Chr7: } \\
95692641 . .95694174\end{array}$ & 354 & 39.7 & 7.39 & ANAC100 & & $6 e-64$ & \\
\hline AiNAC31 & Araip.CC7W1 & $\begin{array}{l}\text { Chr2: } \\
\text { 5953755..5956019 }\end{array}$ & 461 & 51.0 & 6.05 & ANAC33 & & $1 e-90$ & \\
\hline AiNAC32 & Araip.D25HB & $\begin{array}{l}\text { Chr8: } \\
\text { 70326624..70335981 }\end{array}$ & 390 & 44.0 & 6.27 & ANAC58 & & $3 e-66$ & \\
\hline AiNAC33 & Araip.D7N1Q & $\begin{array}{l}\text { Chr6: } \\
\text { 34266288..34267077 }\end{array}$ & 142 & 16.1 & 9.78 & & ANAC25 & $2 e-60$ & \\
\hline AiNAC34 & Araip.DEH65 & $\begin{array}{l}\text { Chr5: } \\
\text { 14567806..14570484 }\end{array}$ & 343 & 39.8 & 6.24 & ANAC7 & & $\begin{array}{l}7 e- \\
117\end{array}$ & \\
\hline AiNAC35 & Araip.DL86S & $\begin{array}{l}\text { Chr8: } \\
\text { 21485570..21487407 }\end{array}$ & 349 & 39.1 & 8.20 & ANAC19 & & $\begin{array}{l}2 e- \\
120\end{array}$ & $\begin{array}{l}\text { AhNAC2 (EU755023) } \\
{[27]}\end{array}$ \\
\hline AiNAC36 & Araip.DR280 & $\begin{array}{l}\text { Chr10: } \\
\text { 126350971..126352623 }\end{array}$ & 304 & 34.7 & 6.66 & ANAC94 & & $3 e-65$ & \\
\hline AiNAC37 & Araip.EONQO & $\begin{array}{l}\text { Chr9: } \\
\text { 131326018..131330122 }\end{array}$ & 494 & 55.1 & 5.05 & & ANAC8 & $\begin{array}{l}5 e- \\
132\end{array}$ & \\
\hline AiNAC38 & Araip.F5AGL & $\begin{array}{l}\text { Chr1: } \\
114413161 . .114414326\end{array}$ & 330 & 37.2 & 8.16 & ANAC100 & & $\begin{array}{l}3 e- \\
137\end{array}$ & \\
\hline AiNAC39 & Araip.F8162 & $\begin{array}{l}\text { Chr9: } \\
127070762 . .127076419\end{array}$ & 425 & 47.9 & 8.63 & ANAC51 & & $1 e-87$ & \\
\hline AiNAC40 & Araip.FRONA & $\begin{array}{l}\text { Chr8: } \\
\text { 128783925..128786313 }\end{array}$ & 116 & 13.5 & 10.25 & & ANAC83 & $1 e-24$ & \\
\hline AiNAC41 & Araip.FRS32 & $\begin{array}{l}\text { Chr6: } \\
\text { 22593548..22597918 }\end{array}$ & 259 & 29.9 & 6.70 & ANAC74 & & $4 e-92$ & \\
\hline AiNAC42 & Araip.G3ZLR & $\begin{array}{l}\text { Chr5: } \\
\text { 12372525.112374201 }\end{array}$ & 321 & 36.7 & 5.21 & ANAC7 & & $2 e-97$ & \\
\hline AiNAC43 & Araip.G88UP & $\begin{array}{l}\text { Chr3: } \\
\text { 120758733..120762390 }\end{array}$ & 330 & 37.3 & 8.47 & ANAC75 & & $4 e-97$ & \\
\hline AiNAC44 & Araip.HIJ9F & $\begin{array}{l}\text { Chr6: } \\
113252685 . .113254364\end{array}$ & 418 & 47.1 & 9.44 & ANAC47 & & $8 e-98$ & \\
\hline AiNAC45 & Araip.HYM8C & $\begin{array}{l}\text { Chr6: } \\
113117048 . .113118424\end{array}$ & 395 & 44.5 & 6.21 & ANAC46 & & $\begin{array}{l}4 e- \\
111\end{array}$ & \\
\hline AiNAC46 & Araip.160BC & $\begin{array}{l}\text { Chr8: } \\
\text { 5732262..5733688 }\end{array}$ & 234 & 26.3 & 6.09 & ANAC90 & & $3 e-64$ & \\
\hline AiNAC47 & Araip.16LH9 & $\begin{array}{l}\text { Chr8: } \\
\text { 126952889..126954575 }\end{array}$ & 318 & 36.7 & 6.01 & ANAC32 & & $2 e-96$ & \\
\hline AiNAC48 & Araip.J93FI & $\begin{array}{l}\text { Chr8: } \\
\text { 10780467..10782598 }\end{array}$ & 294 & 33.5 & 8.82 & ANAC75 & & $2 e-98$ & \\
\hline AiNAC49 & Araip.J9WH5 & $\begin{array}{l}\text { Chr3: } \\
\text { 14391485..14393315 }\end{array}$ & 375 & 42.5 & 7.28 & ANAC70 & & $\begin{array}{l}2 \mathrm{e}- \\
159\end{array}$ & \\
\hline
\end{tabular}


Table 1 NAC TF gene family members in wild Arachis (Continued)

\begin{tabular}{|c|c|c|c|c|c|c|c|c|c|}
\hline $\begin{array}{l}\text { Gene } \\
\text { symbol }\end{array}$ & $\begin{array}{l}\text { Gene model } \\
\text { name }\end{array}$ & Gene location & $\begin{array}{l}\text { Length } \\
\text { (aa) }\end{array}$ & $\begin{array}{l}\text { MW } \\
(\mathrm{kDa})\end{array}$ & $\begin{array}{l}\text { Theoretical } \\
\text { pl }\end{array}$ & $\begin{array}{l}\text { Putative } \\
\text { Arabidopsis } \\
\text { orthologues }\end{array}$ & $\begin{array}{l}\text { Closest } \\
\text { genes }\end{array}$ & $\begin{array}{l}\mathrm{E}- \\
\text { value }\end{array}$ & $\begin{array}{l}\text { Othologous genes } \\
\text { with known function }\end{array}$ \\
\hline AiNAC50 & Araip.KI83M & $\begin{array}{l}\text { Chr5: } \\
\text { 144883533..1448855223 }\end{array}$ & 306 & 34.4 & 5.48 & ANAC40 & & $6 e-83$ & \\
\hline AiNAC51 & Araip.KMOZG & $\begin{array}{l}\text { Chr3: } \\
130519333 . .130520361\end{array}$ & 143 & 16.6 & 7.84 & & ANAC104 & $1 e-57$ & \\
\hline AiNAC52 & Araip.KP5QZ & $\begin{array}{l}\text { Chr3: } \\
\text { 119580802..119582423 }\end{array}$ & 362 & 40.1 & 8.83 & ANAC25 & & $\begin{array}{l}2 \mathrm{e}- \\
111\end{array}$ & \\
\hline AiNAC53 & Araip.ZUP60 & $\begin{array}{l}\text { Chr8: } \\
\text { 105359001..105363289 }\end{array}$ & 350 & 40.5 & 6.73 & ANAC33 & & $\begin{array}{l}4 \mathrm{e}- \\
125\end{array}$ & \\
\hline AiNAC54 & Araip.Z57SD & $\begin{array}{l}\text { Chr9: } \\
127100454 . .127103707\end{array}$ & 593 & 66.4 & 4.66 & ANAC2 & & $6 e-82$ & \\
\hline AiNAC55 & Araip.L2221 & $\begin{array}{l}\text { Chr3: } \\
127136414 . .127138105\end{array}$ & 423 & 47.3 & 6.49 & ANAC94 & & $8 e-97$ & \\
\hline AiNAC56 & Araip.MQD5S & $\begin{array}{l}\text { Chr2: } \\
6609921 . .6613742\end{array}$ & 289 & 33.1 & 5.65 & & ANAC14 & $1 e-39$ & \\
\hline AiNAC57 & Araip.NB7HU & $\begin{array}{l}\text { Chr8: } \\
\text { 21185319..21187122 }\end{array}$ & 332 & 36.9 & 8.67 & ANAC25 & & $\begin{array}{l}2 e- \\
102\end{array}$ & \\
\hline AiNAC58 & Araip.NL359 & $\begin{array}{l}\text { Chr5: } \\
\text { 126310932..126316255 }\end{array}$ & 255 & 29.4 & 5.16 & ANAC86 & & $1 e-78$ & \\
\hline AiNAC59 & Araip.PNX61 & $\begin{array}{l}\text { Chr6: } \\
\text { 135601578..135605205 }\end{array}$ & 308 & 34.8 & 5.61 & & ANAC96 & $8 e-19$ & \\
\hline AiNAC60 & Araip.PT231 & $\begin{array}{l}\text { Chr3: } \\
113538059.113544219\end{array}$ & 343 & 38.0 & 5.85 & ANAC103 & & $1 e-58$ & \\
\hline AiNAC61 & Araip.PW8UQ & $\begin{array}{l}\text { Chr3: } \\
\text { 10649536..10655226 }\end{array}$ & 256 & 29.8 & 5.83 & ANAC36 & & $5 e-98$ & \\
\hline AiNAC62 & Araip.PXOQP & $\begin{array}{l}\text { Chr7: } \\
\text { 29146174..29149324 }\end{array}$ & 573 & 63.3 & 4.59 & & ANAC14 & $1 e-28$ & \\
\hline AiNAC63 & Araip.Q1JTJ & $\begin{array}{l}\text { Chr1: } \\
\text { 50655721..50661455 }\end{array}$ & 377 & 43.5 & 6.24 & ANAC7 & & $\begin{array}{l}2 e- \\
133\end{array}$ & \\
\hline AiNAC64 & Araip.Q3R6H & $\begin{array}{l}\text { Chr8: } \\
\text { 3508743..3510623 }\end{array}$ & 360 & 41.0 & 5.95 & ANAC25 & & $2 e-78$ & \\
\hline AiNAC65 & Araip.QS7JY & $\begin{array}{l}\text { Chr9: } \\
\text { 136867581..136871254 }\end{array}$ & 291 & 34.1 & 6.97 & ANAC7 & & $1 e-83$ & \\
\hline AiNAC66 & Araip.R0657 & $\begin{array}{l}\text { Chr3: } \\
\text { 107857753..107858791 }\end{array}$ & 211 & 23.7 & 9.45 & ANAC83 & & $4 e-63$ & \\
\hline AiNAC67 & Araip.T6ICl & $\begin{array}{l}\text { Chr3: } \\
127434557 . .127435546\end{array}$ & 286 & 32.8 & 8.04 & ANAC25 & & 7e-78 & \\
\hline AiNAC68 & Araip.TLOB5 & $\begin{array}{l}\text { Chr5: } \\
\text { 15820769..15822869 }\end{array}$ & 234 & 26.7 & 5.45 & & ANAC62 & $7 e-20$ & \\
\hline AiNAC69 & Araip.U9RGH & $\begin{array}{l}\text { Chr1: } \\
\text { 124432208..124434079 }\end{array}$ & 403 & 46.1 & 6.86 & ANAC35 & & $\begin{array}{l}1 e- \\
116\end{array}$ & \\
\hline AiNAC70 & Araip.UAOW9 & $\begin{array}{l}\text { Chr10: } \\
\text { 133594504..133595933 }\end{array}$ & 277 & 31.8 & 6.32 & ANAC87 & & $\begin{array}{l}9 e- \\
100\end{array}$ & \\
\hline AiNAC71 & Araip.WV14F & $\begin{array}{l}\text { Chr8: } \\
\text { 79712569..79714789 }\end{array}$ & 342 & 39.4 & 8.70 & ANAC42 & & $4 e-87$ & \\
\hline AiNAC72 & Araip.X2KK1 & $\begin{array}{l}\text { Chr5: } \\
\text { 5593161..5595535 }\end{array}$ & 352 & 39.9 & 5.26 & ANAC71 & & $\begin{array}{l}3 e- \\
108\end{array}$ & \\
\hline AiNAC73 & Araip.XJ3T4 & $\begin{array}{l}\text { Chr10: } \\
118962456 . .118966247\end{array}$ & 342 & 37.6 & 7.70 & ANAC38 & & $4 e-82$ & \\
\hline AiNAC74 & Araip.XJX1I & $\begin{array}{l}\text { Chr8: } \\
\text { 97499988..97504182 }\end{array}$ & 319 & 36.9 & 5.64 & ANAC20 & & $3 e-96$ & \\
\hline AiNAC75 & Araip.XK9AB & $\begin{array}{l}\text { Chr1: } \\
33384496.33387453\end{array}$ & 277 & 31.3 & 5.37 & ANAC71 & & $5 e-99$ & \\
\hline
\end{tabular}


Table 1 NAC TF gene family members in wild Arachis (Continued)

\begin{tabular}{|c|c|c|c|c|c|c|c|c|c|}
\hline $\begin{array}{l}\text { Gene } \\
\text { symbol }\end{array}$ & $\begin{array}{l}\text { Gene model } \\
\text { name }\end{array}$ & Gene location & $\begin{array}{l}\text { Length } \\
\text { (aa) }\end{array}$ & $\begin{array}{l}\text { MW } \\
(\mathrm{kDa})\end{array}$ & $\begin{array}{l}\text { Theoretical } \\
\text { pl }\end{array}$ & $\begin{array}{l}\text { Putative } \\
\text { Arabidopsis } \\
\text { orthologues }\end{array}$ & $\begin{array}{l}\text { Closest } \\
\text { genes }\end{array}$ & $\begin{array}{l}\mathrm{E}- \\
\text { value }\end{array}$ & $\begin{array}{l}\text { Othologous genes } \\
\text { with known function }\end{array}$ \\
\hline AiNAC76 & Araip.XQA0A & $\begin{array}{l}\text { Chr5: } \\
\text { 149488712..149490936 }\end{array}$ & 339 & 39.1 & 6.30 & ANAC7 & & $\begin{array}{l}1 e^{-} \\
113\end{array}$ & \\
\hline AiNAC77 & Araip.XT8UZ & $\begin{array}{l}\text { Chr10: } \\
\text { 4890767..4892438 }\end{array}$ & 365 & 41.6 & 6.43 & ANAC25 & & $2 \mathrm{e}-93$ & \\
\hline AiNAC78 & Araip.ZX5IX & $\begin{array}{l}\text { Chr6: } \\
\text { 7136977..7138554 }\end{array}$ & 259 & 29.1 & 6.27 & & ANAC62 & $3 e-10$ & \\
\hline AiNAC79 & Araip.YS3WM & $\begin{array}{l}\text { Chr10: } \\
\text { 10330806.10332162 }\end{array}$ & 229 & 26.7 & 5.69 & ANAC104 & & $1 e-90$ & \\
\hline
\end{tabular}

from 4.57 to 10.25 . Detailed information on the NAC genes in A.duranensis and A. ipaensis is provided in Table 1, including gene location, and putative Arabidopsis orthologues.

As shown in Fig. 1, the $A d N A C$ and $A i N A C$ genes are distributed non-randomly across 10 chromosomes of $A$. duranensis (A genome) and $A$. ipaensis (B genome). In these species, chromosome A3 contained the most NAC genes (16), while chromosome A4 contained the fewest NAC genes (2) (Fig. 1b). In A. ipaensis, 17 genes were distributed on chromosome B3, whereas only one NAC gene was found on chromosome B4 (Fig. 1c).

NAC orthologues are located at syntenic loci within the $A$. duranensis and $A$. ipaensis genomes

We detected 51 orthologous gene pairs according to the phylogenetic relationships of the $A d N A C$ and $A i N A C$ genes (Fig. 2, Table 2) and further confirmed through their chromosomal location and gene structure. Among these orthologous gene pairs, 46 were located at syntenic loci on the $A$. duranensis and $A$. ipaensis chromosomes (Fig. 1a). However, the location of 9 AdNAC genes did not correspond to the location of their orthologous gene in A. ipaensis. For example, $A d N A C 7$ located on chromosome A7, while its orthologous gene in A. ipaensis, AiNAC53, is located on chromosome B8. This finding suggested that large chromosomal rearrangement in the diploid peanut genomes has occurred. Moreover, gene pairs with low identity might result from different splicing patterns or premature stop codons that originated from the released incomplete genome draft [1].

\section{Phylogenetic analysis, gene structure and conserved motifs of Arachis NAC genes}

To explore the relationships among the NACs of two wild Arachis species and predict their potential functions, the full-length NAC proteins from $A$. duranensis (Additional file 5), A. ipaensis (Additional file 5), Arabidopsis (dicot) (Additional file 6) and rice (monocot) (Additional file 7) were subjected to a multiple sequence alignment. The phylogenetic tree divided NACs from wild peanut into 18 distinct subgroups (NAC-a to NACr) along with their Arabidopsis and rice homologues (Fig. 2). In general, the Arabidopsis, rice and peanut NAC proteins were distributed uniformly in all subgroups. However, the NAC-o and NAC-r subgroups contained only Arabidopsis and rice NACs and no peanut NACs. Remarkably, the NAC-p subfamily included 36 rice NACs but only 1 AdNAC and 1 Arabidopsis NAC, while no rice NAC was found in the NAC-n subgroup. Another phylogenetic tree based on the conserved NAM domain is shown in Additional file 8 .

To investigate the structural diversity of NAC genes, the exon/intron structure among the peanut NAC genes was analysed accompanying with their phylogenetic similarities (Fig. 3). All the NAC genes from A.duranensis and $A$. ipaensis were classified into twelve subfamilies (Fig. 3a). Commonly, orthologous genes from A.duranensis and $A$. ipaensis shared similar exon/intron structures including intron number and exon length, for example, AdNAC80 and AiNAC9 in subfamily I, AdNAC59 and AiNAC59 in subfamily III, while $A d N A C 81$ and $A i N A C 29$ in subfamily IV (Additional file 9). Gene structural analysis indicated that the intron distribution within the peanut NAC genes was diverse and varied from 1 to 9 (Fig. 3b). In general, most of the NACs contained 2-3 introns; for instance, 77 genes contained 2 introns, and 43 genes contained 3 introns.

To determine the diversification of NAC genes further, putative motifs were predicted, and ten conserved motifs within the Arachis NAC proteins were analysed (Additional file 10). As expected, the motif compositions among the closely related members were common. For instance, the majority of NAC proteins in subfamily XII contained 8 motifs. Notably, most of the predicted motifs were located in the $\mathrm{N}$-terminal region of the NAC domain, which indicated that the $\mathrm{N}$-terminal region was critical for the function of NAC genes (Fig. 3c).

\section{Cis-acting elements in the promoter region of Arachis NAC genes}

NAC genes play critical roles in the response to numerous stresses. The putative cis-acting elements involved in 


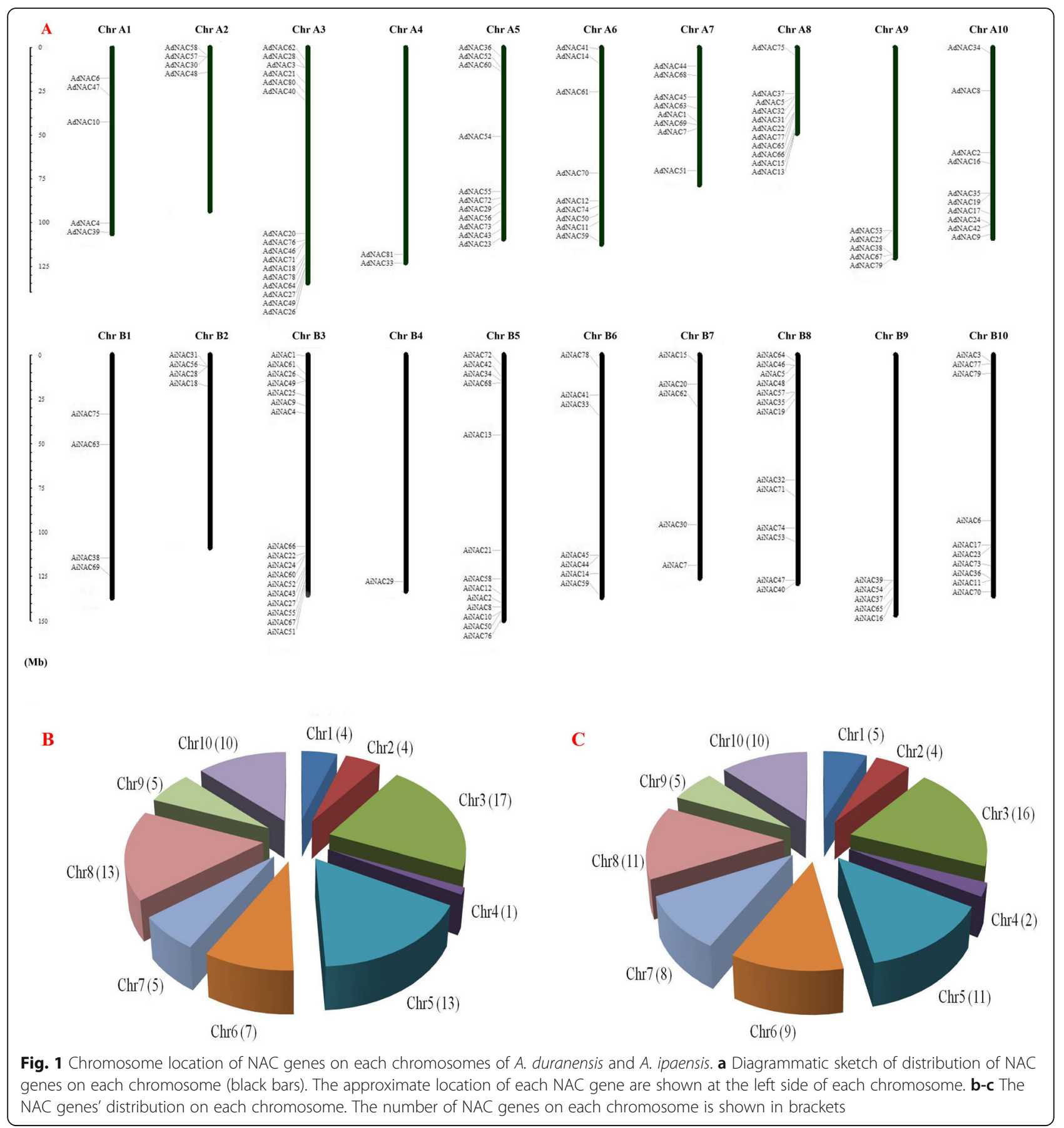

the response to biotic or abiotic stresses within the 2.5$\mathrm{kb}$ sequence upstream of the start codon (ATG) (Additional file 11) were analysed. As shown in Additional files 12, 14 known stress-related cis-acting elements within the promoters of these NAC genes were identified. The numbers of cis-acting factors ranged from 0 to 10 , and there were 10 different types of cisacting elements within the promoter region of AdNAC34, AdNAC30, and AiNAC30. Only promoters of 4 genes (AdNAC7, AdNAC15, AdNAC44, and AiNAC15) contained the TC-rich motif, which is involved in defence and stress responses [42]. Of the 160 promoters, 133 had 1-9 copies of AREs, which are essential for anaerobic induction [43]. The CGTCA motif, which is involved in stress responses mediated by the hormone methyl jasmonate (MeJA) [44], was present within 93 genes. Several other elements related to abiotic and biotic stress responses, such as TGA, W1, HSE, and LTR elements, were also found in these $2.5-\mathrm{kb}$ promoter regions. These results indicated that NAC genes were 


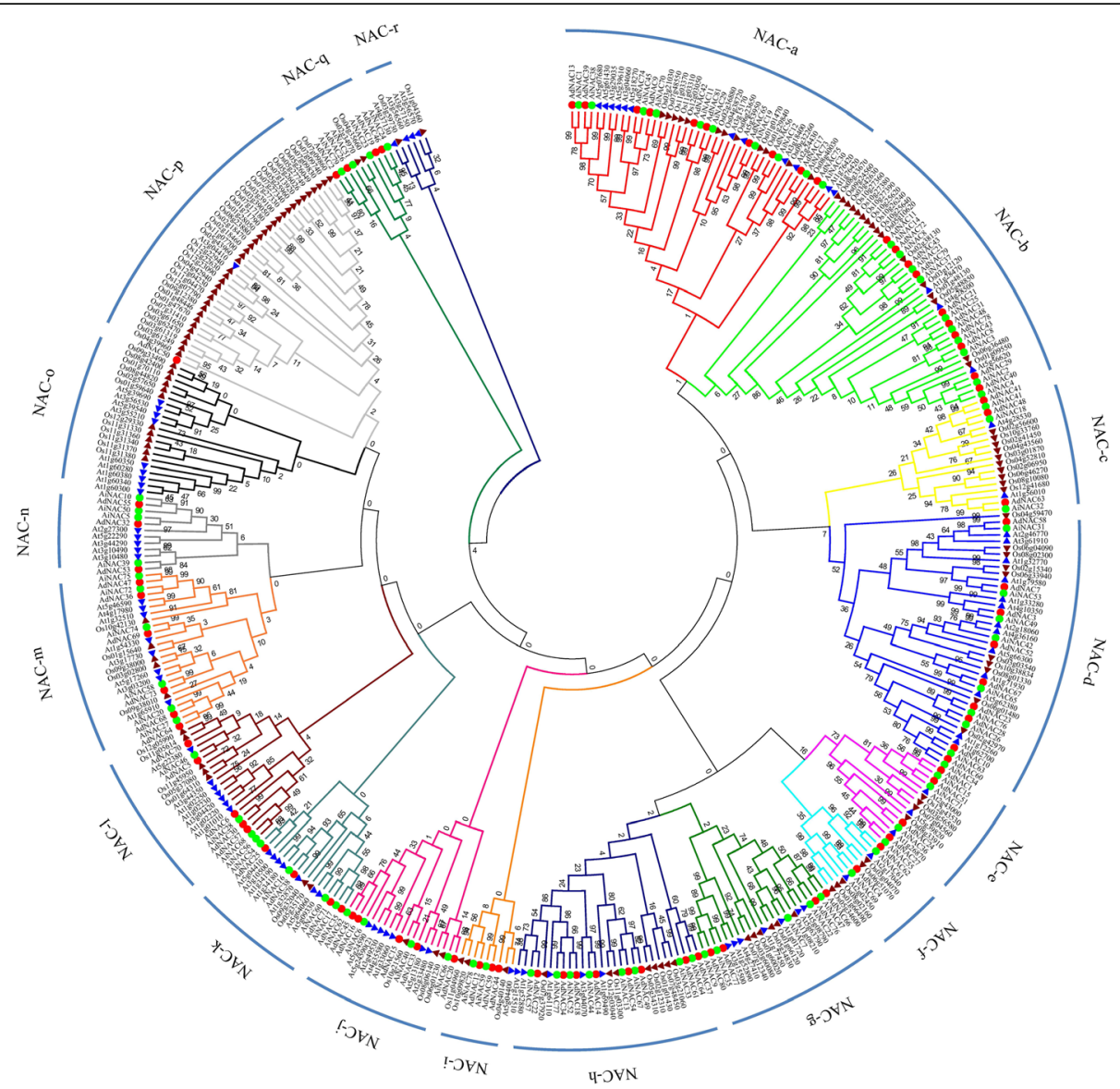

Fig. 2 Phylogenetic analysis of NAC proteins among Arachis, Arabidopsis and rice. Multiple sequence alignment of NAC proteins was performed using ClustalW. The phylogenetic tree was constructed via MEGA 6.0 using NJ method with 1000 bootstrap replicates. The tree was divided these NAC proteins into 18 subgroups, designated NAC-a to NAC-r. NAC protein members of A. duranensis, A. ipaensis, Arabidopsis and rice are distinguished by red circles, green circles, blue triangles, and brown triangles, respectively

transcriptionally regulated in response to biotic and abiotic stresses.

\section{Expression profile of NAC genes in different tissues of $A$. duranensis and $A$. ipaensis}

To investigate the tissue-specific expression profile of NAC genes, we utilized transcriptome data from Clevenger et al. [36]. The examined 22 tissues encompassed nearly all tissues and developmental stages. As shown in Fig. 4, there was no detection of AdNAC44 expression in any of the 22 tissues. Twenty-three NAC genes were expressed at a relatively high level in the 22 tissues. Among these 23 genes, AiNAC7 exhibited relatively high expression levels in all 22 tissues, while its homologue AdNAC12 was expressed only in reproductive shoot tip tissue. The genes with the same expression patterns, for example, $A d N A C 16$ and AiNAC6, were classified into the same group (group V, Fig. 3). Moreover, some NAC genes displayed tissue-specific or preferential expression patterns. For example, AdNAC58 was not expressed in the seeds, pistils or stamens. This tissue-specific expression data analysis could ultimately help determine the locations of the regulatory function of NAC genes.

\section{Mining NAC genes involved in the response to salt and drought stresses}

Many NAC genes are considered to be abiotic stresseresponsive genes. To explore NAC genes involved in the response to salt and/or drought stresses, we analysed the published transcriptome sequencing results of cultivated peanut under salt [39] and drought [37] treatments. Under salt treatment, the expression level of 28 genes was upregulated by 2 -fold, whereas the expression of 15 genes was downregulated more than 2-fold. The expression of 8 genes was significantly upregulated more than 5 -fold, and the greatest expression reached 17 -fold, and the expression of 6 genes was downregulated more than 5-fold (Fig. 5, Additional file 13). Under drought treatment, the expression of 30 genes was up-regulated more than 2-fold, the expression of 9 genes was up-regulated 
Table 2 Putative orthologous gene pairs in A. duranensis and A. ipaensis

\begin{tabular}{|c|c|c|c|c|}
\hline Gene pairs & Groups & Chromosome & CDS identity (\%) & Protein identity (\%) \\
\hline AdNAC1-AiNAC15 & $I X-I X$ & $7-7$ & 62.33 & 73.17 \\
\hline AdNAC2-AiNAC79 & $I X-\mid X$ & $10-10$ & 96.73 & 99.13 \\
\hline AdNAC3-AiNAC49 & VIII-VIII & $3-3$ & 96.09 & 96.35 \\
\hline AdNAC4-AiNAC69 & $I X-I X$ & $1-1$ & 95.51 & 96.30 \\
\hline AdNAC7-AiNAC53 & $\mathrm{VI}-\mathrm{VI}$ & $7-8$ & 97.68 & 97.43 \\
\hline AdNAC10-AiNAC63 & $x-X$ & $1-1$ & 79.17 & 73.47 \\
\hline AdNAC12-AiNAC78 & VIII-VIII & $6-6$ & 93.89 & 85.71 \\
\hline AdNAC16-AiNAC6 & $V-V$ & $10-10$ & 98.67 & 99.16 \\
\hline AdNAC17-AiNAC73 & $\|||-|| \mid$ & $10-10$ & 90.02 & 88.27 \\
\hline AdNAC18-AiNAC52 & $V-V$ & $3-3$ & 84.50 & 86.74 \\
\hline AdNAC20-AiNAC66 & $H$ & $3-3$ & 96.68 & 98.58 \\
\hline AdNAC21-AiNAC25 & $I X-I X$ & $3-3$ & 89.14 & 84.78 \\
\hline AdNAC22-AiNAC57 & $H$ & $8-8$ & 95.67 & 94.58 \\
\hline AdNAC23-AiNAC76 & $x-X$ & $5-5$ & 93.51 & 95.07 \\
\hline AdNAC24-AiNAC36 & $\|||-|| \mid$ & $10-10$ & 86.73 & 84.76 \\
\hline AdNAC25-AiNAC54 & $\|-\|$ & $9-9$ & 94.42 & 94.01 \\
\hline AdNAC28-AiNAC26 & $\mathrm{VI}-\mathrm{VI}$ & $3-3$ & 87.92 & 87.77 \\
\hline AdNAC29-AiNAC2 & VIII-VIII & $5-5$ & 76.79 & 74.10 \\
\hline AdNAC34-AiNAC77 & $\mathrm{XI}-\mathrm{XI}$ & $10-10$ & 91.48 & 88.28 \\
\hline AdNAC35-AiNAC17 & $X\|-X\|$ & $10-10$ & 98.64 & 98.91 \\
\hline AdNAC36-AiNAC72 & $X\|-X\|$ & $5-5$ & 97.76 & 97.19 \\
\hline AdNAC37-AiNAC64 & $\|||-|| \mid$ & $8-8$ & 98.89 & 99.17 \\
\hline AdNAC39-AiNAC38 & $\|||-|| \mid$ & $1-1$ & 98.39 & 99.39 \\
\hline AdNAC40-AiNAC4 & $\mathrm{VI}-\mathrm{VI}$ & $3-3$ & 97.46 & 96.60 \\
\hline AdNAC47-AiNAC75 & $X I I-X \|$ & $1-1$ & 82.03 & 80.36 \\
\hline AdNAC48-AiNAC41 & $\mathrm{VI}-\mathrm{VI}$ & $2-6$ & 61.05 & 55.21 \\
\hline AdNAC49-AiNAC67 & $X\|-X\|$ & $3-3$ & 95.76 & 98.60 \\
\hline AdNAC52-AiNAC42 & $X\|-X\|$ & $5-5$ & 94.43 & 92.97 \\
\hline AdNAC53-AiNAC39 & $\|-\|$ & $9-9$ & 98.54 & 98.82 \\
\hline AdNAC54-AiNAC13 & VIII-VIII & $5-5$ & 97.08 & 99.35 \\
\hline AdNAC55-AiNAC10 & $\| I I-|| \mid$ & $5-5$ & 69.45 & 43.90 \\
\hline AdNAC56-AiNAC12 & $\|-\|$ & $5-5$ & 96.01 & 95.91 \\
\hline AdNAC57-AiNAC56 & $\mathrm{XI}-\mathrm{XI}$ & $2-2$ & 85.78 & 80.97 \\
\hline AdNAC58-AiNAC31 & H & $2-2$ & 97.00 & 97.85 \\
\hline AdNAC59-AiNAC59 & $\|||-|| \mid$ & $6-6$ & 97.70 & 97.08 \\
\hline AdNAC62-AiNAC61 & $H$ & $3-3$ & 79.21 & 79.05 \\
\hline AdNAC63-AiNAC32 & $X I I-X I I$ & $7-8$ & 76.35 & 68.29 \\
\hline AdNAC64-AiNAC27 & $X I I-X I I$ & $3-3$ & 97.04 & 97.79 \\
\hline AdNAC65-AiNAC19 & IV-IV & $8-8$ & 97.82 & 97.57 \\
\hline AdNAC67-AiNAC65 & $x-X$ & $9-9$ & 83.21 & 84.80 \\
\hline AdNAC68-AiNAC20 & $X I I-X I I$ & $7-7$ & 98.61 & 97.94 \\
\hline AdNAC69-AiNAC74 & $X I I-X I I$ & $7-8$ & 80.24 & 76.57 \\
\hline AdNAC73-AiNAC58 & $X\|-X\|$ & $5-5$ & 65.10 & 58.43 \\
\hline AdNAC74-AiNAC45 & $H$ & $6-6$ & 98.99 & 98.74 \\
\hline
\end{tabular}


Table 2 Putative orthologous gene pairs in A. duranensis and A. ipaensis (Continued)

\begin{tabular}{lllll}
\hline Gene pairs & Groups & Chromosome & CDS identity (\%) & Protein identity (\%) \\
\hline AdNAC75-AiNAC30 & IV-IV & $8-7$ & 89.36 & 85.87 \\
AdNAC76-AiNAC22 & X-X & $3-3$ & 98.19 & 99.23 \\
AdNAC77-AiNAC35 & I-I & $8-8$ & 97.32 & 99.71 \\
AdNAC78-AiNAC43 & IV-IV & $3-3$ & 93.50 & 94.07 \\
AdNAC79-AiNAC37 & V-V & $9-9$ & 97.04 & 95.98 \\
AdNAC80-AiNAC9 & I-I & $3-3$ & 98.80 & 99.40 \\
AdNAC81-AiNAC29 & IV-IV & $4-4$ & 97.32 & 96.97 \\
\hline
\end{tabular}

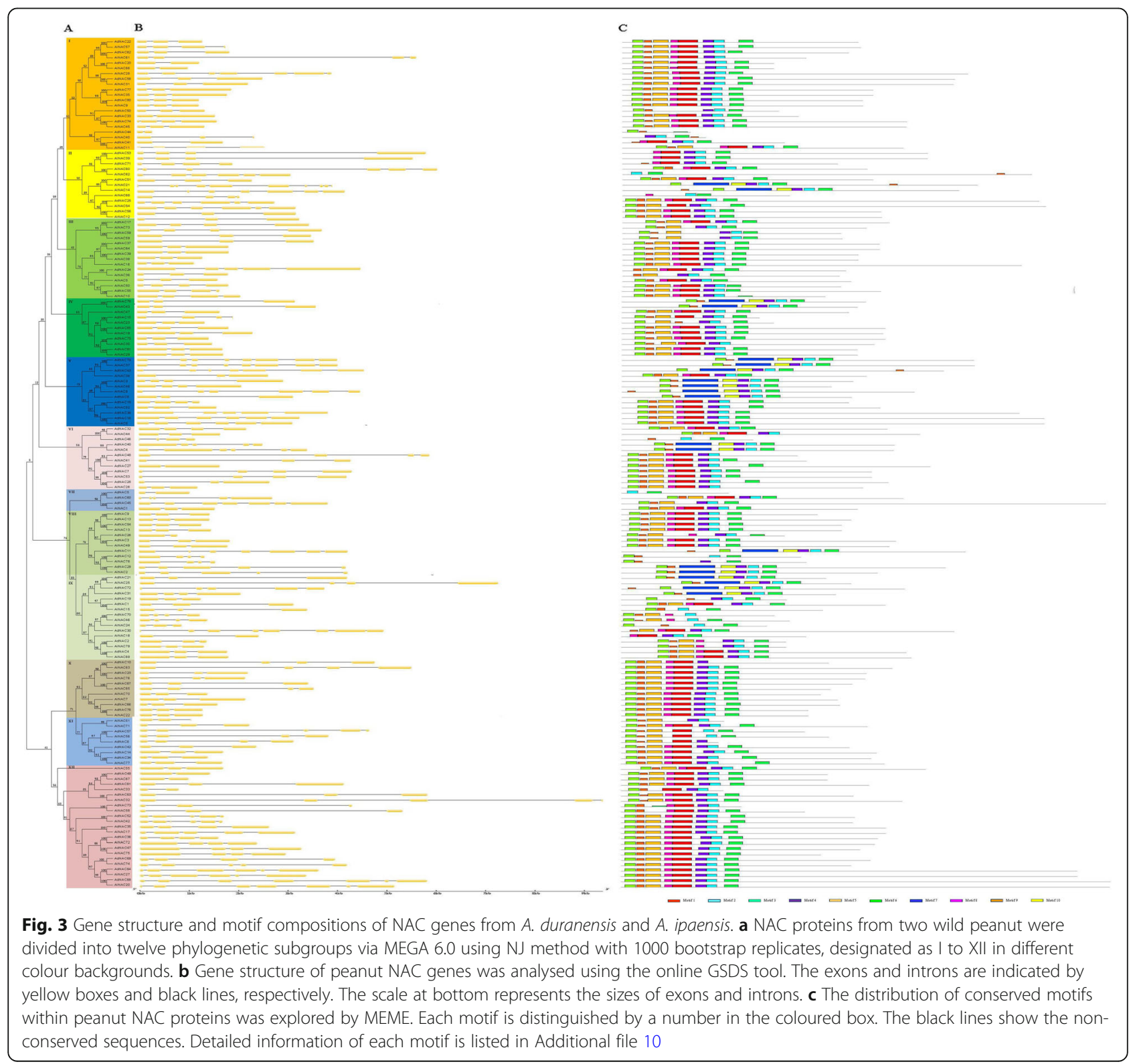




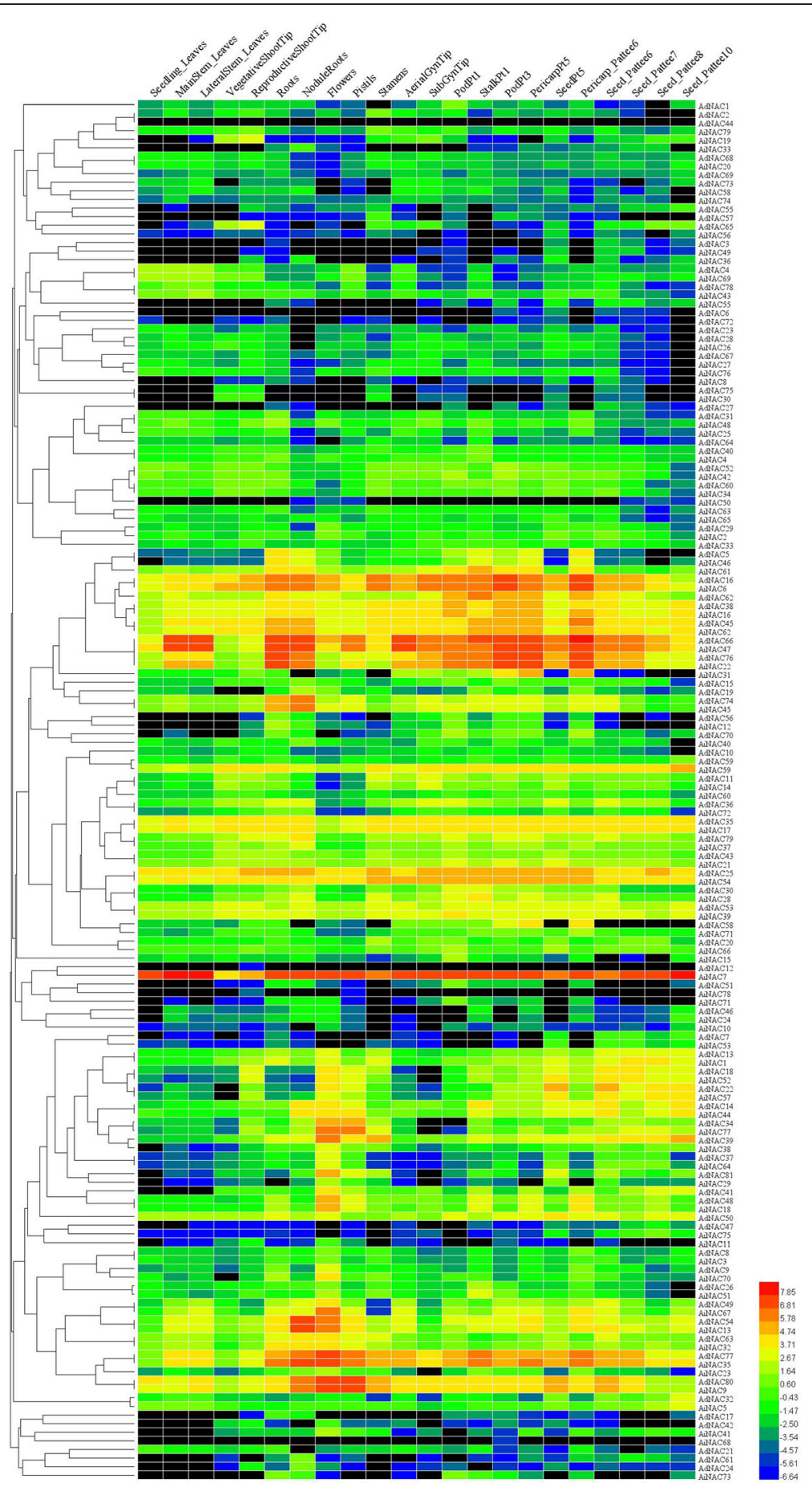

Fig. 4 Tissue-specific expression pattern of NAC genes in 22 different tissues and development of two wild peanuts. The illumina RNA-seq data from Clevenger et al. [36] were reanalysed, the average FPKM values were log2 transformed and a heatmap was obtained using Heml. The expression intensity shows in different colours (red, high expression; green, low expression; black, no expression). The bar at the top represents 22 different tissues and developmental stages; NAC genes from A. duranensis and A. ipaensis are shown on the right

more than 10-fold, and the greatest expression reached 38 -fold. The expression of 13 genes was down-regulated more than 2-fold, and the greatest expression reached 15-fold (Fig. 5, Additional file 14). The expression of 17 genes was found to be responsive to both salt and drought stresses. Four genes (AhNAC1, AhNAC37, AhNAC83 and AhNAC156) displayed the opposite response to salt and drought stresses (Fig. 5). Information 


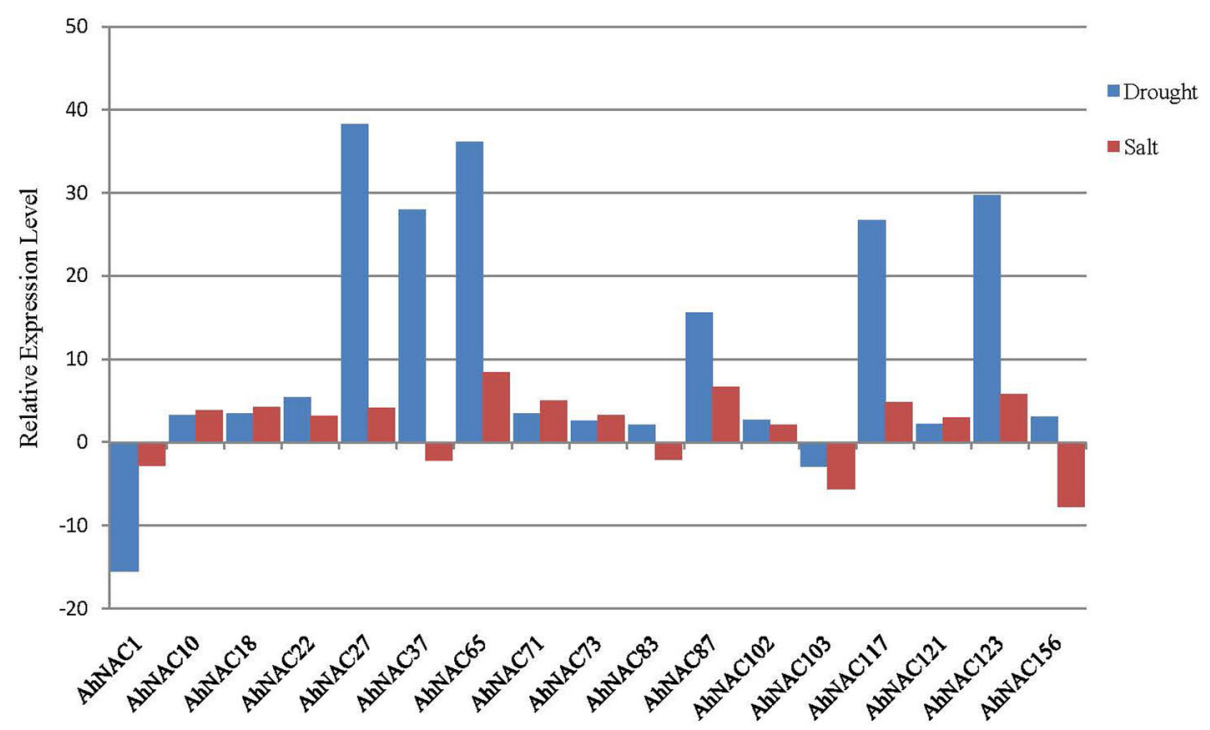

Fig. 5 Expression patterns of AhNAC genes under drought and salt stresses based on RNA-seq data. The Y-axis indicates the relative expression level. The X-axis represnts the genes whose expression was upregulated or downregulated more than 2-fold under both salt and drought treatments in cultivated peanut

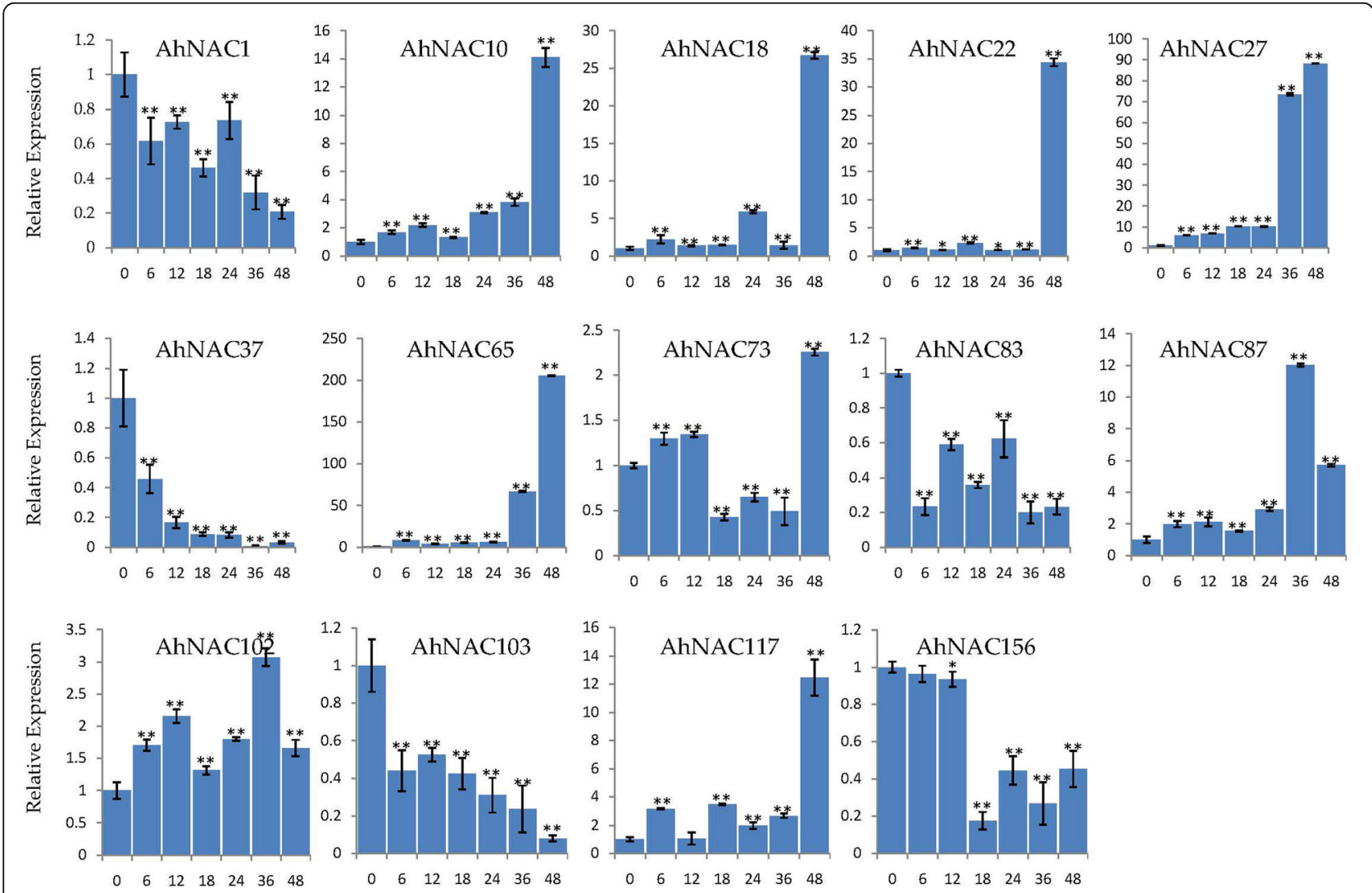

Fig. 6 Expression profiling of AhNAC genes under salt stress. The Y-axis indicates the relative expression level. The X-axis represents hours (0, 6 , $12,18,24,36$, and 48) after salt treatment in cultivated peanut. The actin gene was used as an internal control. The error bars were obtained from three biological replicates, and asterisks represnt the genes whose expression was significantly up- or downregulated under salt stress, according to t-tests $\left(*, p<0.05 ;^{* *}, P<0.01\right.$ ) 
concerning these NAC genes from cultivated A. hypogaea is listed in Additional file 3. These observations indicated that some of the NAC proteins may function in multiple stress responses.

\section{RT-qPCR of NAC genes under salt and drought stresses in cultivated peanut}

To confirm which genes respond to stress for further genetic engineering of cultivated peanut with improved stress resistance, we performed RT-qPCR expression analysis of the root. Several genes were randomly selected from the 17 NAC genes that were involved in both salt and drought stress responses. Under salt stress $(51.33 \mathrm{mM})$ treatment, the expression trends of most of the detected NACs in roots (except the trends of $A h N A C 73)$ were identical to the RNA-seq results. For example, the expression of AhNAC1, AhNAC37, $A h N A C 103$, and AhNAC156 was downregulated under salt stress at all detected time points, while the expression levels of AhNAC10, AhNAC18, AhNAC22, AhNAC27, AhNAC65, AhNAC87, AhNAC102, and $A h N A C 117$ were upregulated. Notably, the expression of AhNAC10, AhNAC18, AhNAC22, AhNAC27, AhNAC65, and $A h N A C 117$ peaked at $48 \mathrm{~h}$ after salt stress treatment, and the increase in expression of AhNAC65 reached more than 200-fold (Fig. 6). Under 20\% PEG6000 treatment, the expression levels of AhNAC10, AhNAC18, AhNAC65, AhNAC73, AhNAC87, and $A h N A C 102$ increased at all subsequent time points after treatment, and the expression level of AhNAC65 increased by nearly 30 -fold after treatment for $24 \mathrm{~h}$ (Fig. 7).
These results were consistent with the RNA-seq results (Fig. 5). Overall, these results indicated that the response of these genes to salt and drought treatment could potentially improve peanut.

\section{Discussion}

\section{Characterization of Arachis NAC genes}

NAC genes are members of one of the largest plant TF families and play critical roles in numerous stress responses $[4,5]$. The NAC gene family has been characterized from several plant genomes $[10-19,40,41]$. However, little is known about NAC genes in Arachis species. Cultivated peanut $A$. hypogaea originated via hybridization of two diploid wild peanut. The A and $\mathrm{B}$ genomes of wild peanut $A$. duranensis (AA) and $A$. ipaensis (BB) are highly identical to the $\mathrm{A}$ and $\mathrm{B}$ subgenomes of cultivated peanut (AABB) [32]. The diploid wild peanuts are more convenient for gene cloning than the allotetraploid cultivated peanut (which contains A and $B$ sub-genomes) because the diploids contain only one genome set (AA or BB). The available RNA-seq data of 22 distinct tissue types of the wild peanut A.duranensis and A.ipaensis made it convenient for gene expression profiling analysis [36]. Therefore, in this study, we performed a genome-wide analysis of NAC TFs from wild peanut and explored their orthologous genes' potential functions in response to salt and drought stress in cultivated peanut. Information (for example, chromosomal location, gene structure, tissue expression profiles) of NAC genes from cultivated peanut could be deduced

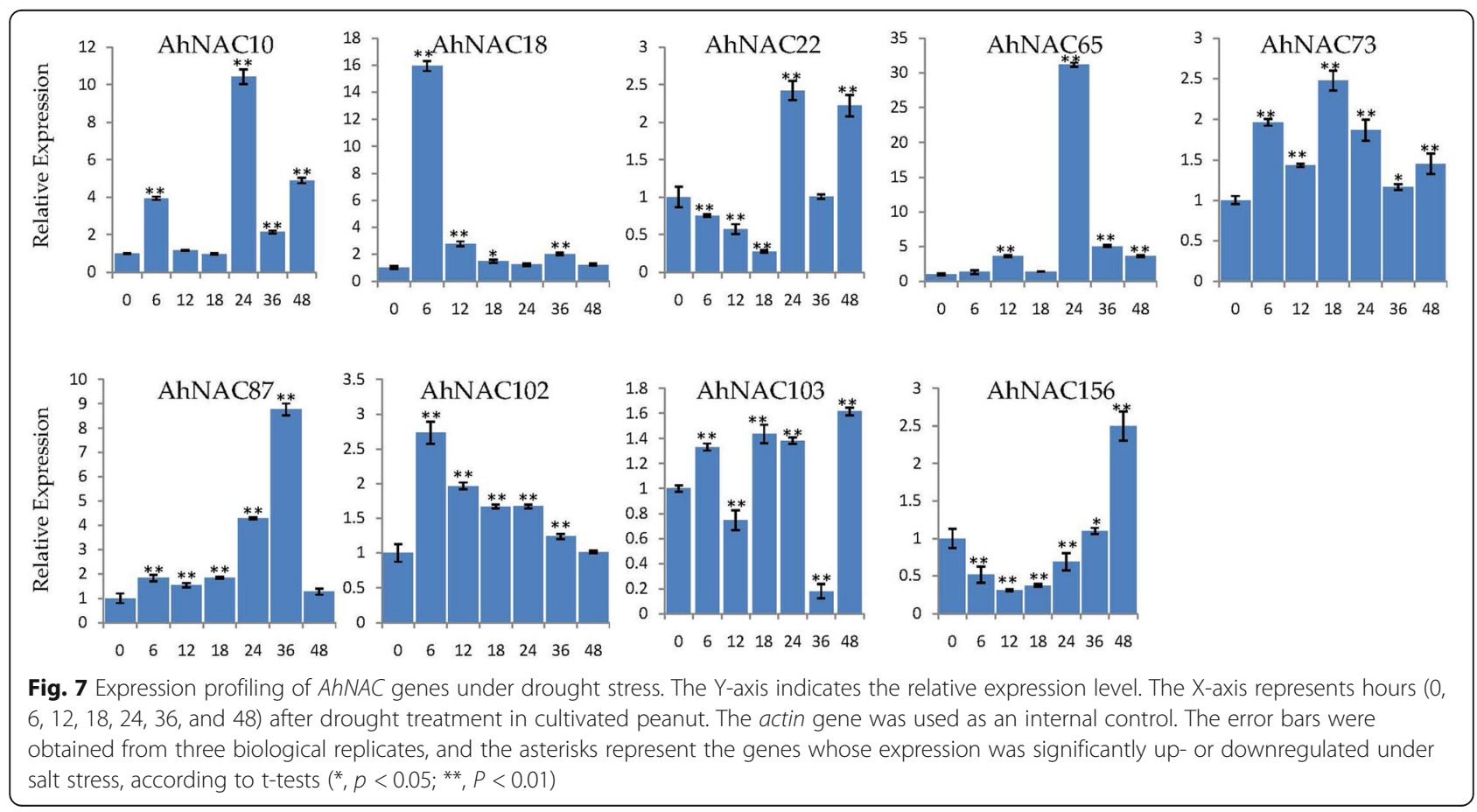


from the orthologous genes of wild peanut from this study.

In total, 81,79 and 164 NAC TFs were identified from the wild peanut species A.duranensis, A. ipaensis and cultivated peanut $A$. hypogaea, respectively. Two or more peanut NAC genes were found for every orthologue in Arabidopsis. Detailed information on the Arachis NAC gene family, including model name, location, nucleotide acid length, molecular weight and theoretical pI, as well as Arabidopsis orthologues is listed in Table 1 and Additional file 3. A previous study showed that the number of nucleotide-binding site (NBS) domains characteristic of biotic stress resistance genes in tetraploid peanut was less than the sum of them between $A$. duranensis and A. ipaensis and caused some resistance abilities lost in cultivated peanut [32]. However, in our study, the number (164) of NACs in A.hypogaea was nearly the sum of those between wild A. duranensis (81) and A. ipaensis (79). This expansion might arise from multiple gene duplication events, including wholegenome duplication in the Arachis lineage followed by multiple segmental and tandem duplication events [27, 32]. These results were identical to those NAC from cultivated cotton Gossypium barbadense and two diploid cotton species, Gossypium rainondii and Gossypium arboreum [45]. Previous studies revealed that the involvement of NAC genes performed major functions in transcription regulation [45]. Thus, we speculated that NACs might perform functions through regulating stress-resistant-related genes or proteins, while not performing functions like a "on-off" switch. The number of NAC genes in cultivated peanut (164) was larger than that in other plant species (for example, 105 in Arabidopsis [40], 141 in rice [41], and 101 in soybean [46]), which was approximately 1.56-fold than that in Arabidopsis, and a similar result was found in Populus [10]. The NAC gene density in A.duranensis, A. ipaensis and A.hypogaea $(0.07 / \mathrm{Mb}, 0.05 / \mathrm{Mb}, 0.06 / \mathrm{Mb})$ was lower than that in Arabidopsis $(0.87 / \mathrm{Mb})$ and rice $(0.37 / \mathrm{Mb})$ [11]. This may be attributed to Arachis large genome sizes, which suggested that the genome size and number of NAC family members were not always correlated. These NAC genes were unevenly distributed on each Arachis chromosome (Fig. 1). The numbers on each chromosome ranged from 1 to 17 , which indicated that there was no positive correlation between chromosome length and the number of NAC genes. Some NAC genes, such as AdNAC58, AdNAC57 and AdNAC30, tended to be located in clusters on the chromosome, these gene therefore might function cooperatively [47].

Tissue-specific expression profiling were useful because it identified the genes that were involved in defining the precise nature of individual tissues [48]. In this study, we utilized the published available RNA-seq data of 22 tissue types to examine the specific expression patterns of Arachis NAC genes [36]. Twenty-three NAC genes were ubiquitously expressed, which could serve as a platform to regulate a broad set of genes that were subsequently fine tuned by specific regulators. Notably, we found that AdNAC58 was not expressed in seeds, pistils or stamens, which indicated that its promoter could be used for non-seed genetic engineering.

\section{Phylogenetic analysis and expression profiling of Arachis NAC genes under salt and drought stress}

We performed phylogenetic analysis of Arachis NAC with monocot (rice) and dicot (Arabidopsis) model plant species to investigate the evolutionary relationships and predict drought- or salt-responsive genes. In the present study, these NACs were classified into 18 subgroups, which was largely consistent with the results of previous analyses $[10,40,41]$. Remarkably, the subfamily NAC-p included 36 rice $N A C$ s but only $1 A d N A C$ and 1 Arabidopsis NAC (Fig. 2), which suggested that they might have been either acquired in the rice or lost in Arabidopsis and Arachis when they split from their common ancestor. In contrast, there was no rice NAC gene in the subfamily NAC-n (Fig. 2), suggesting that diversification and expansion of this subgroup occurred after the monocot-dicot divergence. This phenomenon has also been found in radish, Populus and other species [10, 11].

If the $A d N A C$ and $A i N A C$ genes were clustered in pairs in phylogenetic tree, the gene pairs were considered as orthologous genes $[49,50]$. In this study, 51 orthologous genes were identified from two wild peanut according to the phylogenetic relationship of the $A d N A C$ and $A i N A C$ genes (Fig. 2, Table 2), which accounted for more than $57 \%$ of the entire family, with sequence identities ranging from 61 to $99 \%$ (Table 2), Forty-six genes were located at syntenic loci and exhibited high collinearity on the $A$. duranensis and A. ipaensis chromosomes (Table 2, Fig. 1). Several putative orthologous gene pairs exhibited low coding DNA sequence (CDS) or low protein identity, which could be attributed to wrong exon-intron splicing originating from genome sequencing mistakes (for example, AdNAC55 and its orthologous $A i N A C 10)$. Several NAC genes from both wild peanut species were not located in the corresponding chromosome regions, suggesting the occurrence of large chromosomal rearrangement in the diploid genomes. Orthologous genes ususally exhibit similar characteristics and expression patterns [49, 51]. The functions of orthologous NAC genes of cultivated species which derived from two wild species may be redundant. For example, AdNAC54 and AiNAC13 from subfamily VIII have 3 exons and shared the same conserved motif. Both were highly expressed in nodule roots and flowers, but expression at a relatively low levels of in 
the other organs, which was similar to the results of its corresponding Arabidopsis orthologs NAC2 which expressed in roots and flowers with respect to regulating the salt stress response and lateral root development [52]. Additionally, $A N A C 2$ can also be induced by abscisic acid (ABA), 1-aminocyclopropane-1-carboxylic acid (ACC) and 1-naphthylacetic acid (NAA) [52]. Their corresponding orthologous genes in cultivated peanut may function together. Orthologous genes from different plant species showed a tendency to fall into one subgroup and shared similar functions. Many NAC genes have been functionally characterized in Arabidopsis, and their orthologous genes in Arachis were identified in this study (Table 1). Together with the phylogenetic results, it was possible to predict the functions of peanut NAC genes on the basis of the functions of their Arabidopsis and rice orthologues, which could also be potentially utilized for further functional studies. For example, AdNAC77, AiNAC9, and AiNAC35, together with their Arabidopsis orthologous gene, ANAC19 (At1g52890) gene were clustered into the same NAC-g subfamily (Fig. 2). The expression of ANAC19 was induced by drought, high salinity, and abscisic acid (ABA). In the same subfamily, the expression of Arabidopsis ANAC55 (At3g15500) and ANAC72 (At4g27410) was also induced by drought and high salinity [8]. Therefore, we speculated that AdNAC77, AiNAC9, and AiNAC35 are drought- and high salinity-responsive genes that regulate peanut survival under adverse growth conditions. Not surprisingly, AhNAC87 (the orthologous gene of $A d N A C 77$ and AiNAC35 in cultivated peanut) was induced under both salt and drought treatments based on RNA-seq analysis (Fig. 5), and the RT-qPCR-based results confirmed that, in cultivated peanut, the expression of $A h N A C 87$ was upregulated under both salt and drought stress treatments (Figs. 6 and 7). Additionally, Arabidopsis ANAC2 (At1g01720, also known as ATAF1), which is orthologous to $A d N A C 22$, was induced by drought stress [53]. The expression of their orthologue AhNAC37, was upregulated approximately 27.5-fold under drought stress according to the comparative RNA-seq analysis (Fig. 5). These findings strongly supported that the functions of Arachis NAC genes could be deduced from these orthologous genes from Arabidopsis and rice.

Previous reports have provided strong evidence for phylogenetic analysis based prediction of the stressrelated function of several gene family members. The dehydration-induced gene AhNAC3 (EU755022, AhNAC117 in our study) provided hyper-resistance to dehydration and drought stresses [27]. In our study, the expression of AhNAC117 was induced under salt treatment based on the comparative RNA-seq data (Fig. 5), and was confirmed by RT-qPCR (Figs. 6 and 7). Similar results were found for AhNAC4 (HM776131, the orthologue of $A h N A C 87$ in our study, and orthologous to AdNAC77 and AiNAC35) and AhNAC2 (EU755023) [28, 29]. These two genes shared $97.78 \%$ similarity, were highly induced by drought and salt stresses, and conferred drought and salt tolerance to transgenic plants.

\section{Methods}

\section{Sequence database searches}

The sequences of all NAC genes in this study were retrieved from the PeanutBase database (www.peanutbase. org) using the NAM domain (PF02365) as a search query. We verified the putative candidate proteins manually using the NCBI database (https://www.ncbi. nlm.nih.gov/) to confirm the presence of NAM domain. Each protein sequence was examined via the Simple Modular Architecture Research Tool (SMART; http:// smart.embl-heidelberg.de/) domain analysis program and the Pfam (Protein family: http://pfam.xfam.org/) database to confirm the reliability of the search results. Only the sequences containing these domains were retained. The MWs and pIs of each protein were predicted by proteomic and sequence analysis tools on the ExPASy Proteomics Server (http://web.expasy.org/compute_pi/). The putative Arabidopsis orthologues of peanut NACs were identified via BLASTp searches.

\section{Sequence alignment and phylogenetic analysis}

To study the phylogenetic relationships between NAC proteins from peanut and those from dicot Arabidopsis and monocot rice, the Arabidopsis NAC protein sequences were downloaded from The Arabidopsis Information Resource (TAIR; https://www.arabidopsis.org/) and the rice NAC protein sequences were downloaded from the Rice Genome Annotation Project (RGAP; http://rice.plantbiology.msu.edu/). Full length amino acid sequence multiple alignments were performed by the ClustalW program. Unrooted phylogenetic trees were constructed using the neighbour-joining (NJ) method by MEGA 6.0 software, and the bootstrap test was carried out with 1000 iterations.

\section{Chromosomal locations, gene structure and conserved motif analysis}

The chromosomal location information of NAC genes was retrieved from the PeanutBase website (www.peanutbase.org). These genes were mapped onto the chromosomes via the MapInspect program (http:// mapinspect.software.informer.com). Information concerning both the mRNA and gDNA of the peanut NAC genes was obtained from the PeanutBase database (www. peanutbase.org). We used the GSDS (http://gsds.cbi.pku. edu.cn) online program to explore the exon/intron organization of the NAC genes. The MEME (http:// 
meme-suit.org) program was used to investigate the motifs within the NAC protein sequences. The domains in all the protein sequences were analysed via Pfam 31.0 (http://pfam.xfam.org/) based on the hidden Markov model.

\section{Prediction of cis-acting elements within promoters}

Promoter sequences $(2.5 \mathrm{~kb}$ in length) were download from the PeanutBase website (www.peanutbase.org) for cis-acting element analyses. The numbers of several elements related to biotic and abiotic stress responses were identified via New PLACE (https://sogo.dna.affrc.go.jp/ cgi-bin $/$ sogo.cgi?lang $=$ en $\& p j=640 \&$ action $=$ page\&page $=$ newplace) [54].

\section{RNA-seq-based expression profiling of NAC genes in peanut}

The average fragments per kilobase per million reads mapped (FPKM) values of 22 distinct tissue types and developmental stages were obtained from the study by Clevenger et al. [36]. The FPKM values of each NAC gene were $\log 2$ transformed and displayed in the form of heatmaps via HemI [55].

To investigate the expression patterns of NAC genes under salt and drought stress treatments, the average FPKM values of each gene under salt [37] and drought [39] treatments were obtained from our previous work. The average FPKM values of these NAC genes whose expression changed by more than twofold were compared via Excel software, $\log 2$ transformed and displayed in the form of heatmaps using HemI [55].

Plant materials, growth conditions and stress treatments 'Huayu 9303', a cultivated peanut bred by our team, was grown in a temperature-controlled chamber at $20^{\circ} \mathrm{C}$ with a photoperiod of $16 \mathrm{~h}$ of light and $8 \mathrm{~h}$ of darkness unless stated otherwise. After approximately 1 month, the plants were treated with $51.33 \mathrm{mM} \mathrm{NaCl}$ (for salt treatment) or $20 \%$ polyethylene glycol (PEG) 6000 (for drought treatment). The roots were collected after 0,6 , $12,18,24,36$, and $48 \mathrm{~h}$ of treatment, immediately frozen in liquid nitrogen and stored at $-80{ }^{\circ} \mathrm{C}$.

\section{RNA extraction and RT-qPCR based analysis}

Total RNA was extracted with a MiniBEST Plant RNA Extraction Kit (Takara, Dalian, China). First-strand cDNAs were synthesized using a PrimeScript RT-PCR Kit (Takara), and qPCR was carried to check the expression levels of AhNAC genes under salt and drought treatments. The reactions mixtures consisted of $2 \mu \mathrm{L}$ of cDNA $(10.3 \mathrm{ng} / \mu \mathrm{L})$, forward and reverse primers $(400$ nM each), $10 \mu \mathrm{L}$ of TB Green Premix Ex Taq II (Takara), and added sterile water to bring total volume to $20 \mu \mathrm{L}$. Amplification was performed on an ABI 7500
Fast Real-Time System (Applied Biosystems, CA, USA) as follows: $50{ }^{\circ} \mathrm{C}$ for $2 \mathrm{~min} ; 95^{\circ} \mathrm{C}$ for $2 \mathrm{~min}$; and 40 cycles of $95^{\circ} \mathrm{C}$ for $15 \mathrm{~s}$ and $60^{\circ} \mathrm{C}$ for $34 \mathrm{~s}$. The specificity of the reactions was verified by melting curve analysis. Gene specific primers for each detected NAC gene for RTqPCR were designed based on the basis of the difference between othologous genes and were listed in Additional file 15. Each gene was performed with three biological replicates. Gene transcript levels were calculated using ${ }^{\Delta \Delta}$ Ct method [56]. Student's t-test was performed to calculate the $\mathrm{P}$ values using SPSS software. When $\mathrm{P}$ was $<0.05$, we considered the NAC genes were differentially expressed genes. To normalize the expression level of the selected NAC genes, actin gene was used as an internal control [47].

\section{Conclusion}

In the present study, a comprehensive analysis including phylogeny, chromosomal location, gene structure, conserved motif, cis-acting elements within promoter regions, and expression profiling of NAC gene family members in two diploid Arachis species was performed. These results provide a useful foundation for future research on Arachis NAC genes. On the basis of comparative RNA-seq and RT-qPCR-based analysis, we also identified NAC genes involved in drought and/or salt stress responses, which could be potentially used for peanut improvement.

\section{Supplementary information}

Supplementary information accompanies this paper at https://doi.org/10. 1186/s12870-020-02678-9.

Additional file 1. mRNA sequence of NAC genes from two wild peanuts.

Additional file 2. gDNA sequence of NAC genes from two wild peanuts Additional file 3. NAC TF gene family members in cultivated peanut. Additional file 4. mRNA sequence of NAC genes from cultivated peanut.

Additional file 5. NAC proteins of two wild peanuts.

Additional file 6. Arabidopsis NAC proteins.

Additional file 7. Rice NAC proteins.

Additional file 8. Phylogenetic tree analysis of NAC proteins among Arachis, Arabidopsis and rice based on conserved NAM domains.

Additional file 9. Exon-intron structure comparison between AdNAC59, AdNAC80, AdNAC81 and their orthologues AiNAC59, AiNAC9, AiNAC29.

Additional file 10. Sequence logos for the conserved motifs within NAC proteins.

Additional file 11. $2500 \mathrm{bp}$ promoter region of NAC genes from two wild peanuts.

Additional file 12. Number of different cis-acting elements present within the promoter of NAC genes.

Additional file 13. Genes involved in the salt response based on comparative RNA-seq data. The Y-axis represents the fold change compared with the level in un-treated plants. The $X$-axis shows the genes 
whose expression was upregulated and downregulated more than 2-fold under salt treatment in cultivated peanut.

Additional file 14. Genes involved in the drought response based on comparative RNA-seq data. The Y-axis represents the fold change compared with the level in untreated plants. The $X$-axis shows the genes whose expression was upregulated or downregulated more than 2-fold under drought treatment in cultivated peanut.

Additional file 15. Primers used in this study.

\section{Abbreviations}

NAC: NAM, ATAF1/2, and CUC2; NAM: No apical meristem; ATAF1/ 2: Arabidopsis thaliana transcription activation factor; CUC2: Cup-shaped cotyledon; TF: Transcription factor; RNA-seq: RNA sequencing; RT-qPCR: Real time quantitative polymerase chain reaction; Gb: Giga-base pair; Mb: Million base pair; aa: Amino acid; kDa: Kilo Dalton; MeJA: Methyl jasmonate; ABA: Abscisic acid; ACC: 1-aminocyclopropane-1-carboxylic acid; NAA: 1naphthylacetic acid; CDS: Coding DNA sequence; MW: Molecular weights; PI: Isoelectric point; RGAP: Rice Genome Annotation Project; TAIR: The Arabidopsis Information Resource; NJ: Neighbor-joining; FPKM: Fragments per kilobase of transcript per million mapped reads; PEG: Polyethylene glycol

\section{Acknowledgements}

We are grateful to the contributors who generated the peanut genome and transcriptome data accessible in public databases and the anonymous reviewers for their comments on the manuscript.

\section{Authors' contributions}

QXS and SHS conceived and designed the research. CLY and CJL performed the bioinformatic analysis. CLY conducted the experiments and drafted the manuscript. XDL and XBZ participated in the molecular analysis. CJL, CXY, JW and QXS contributed to revisions of the manuscript. All the authors have read and approved the final manuscript.

\section{Funding}

This research was funded by the National Natural Science Foundation of China (32001585, 31601336), the Taishan Scholar Funding (ts201712080), the Agro-industry Technology Research System of Shandong Province (SDAIT-0402), and the Innovation Project of Agricultural Science and Technology of Shandong Academy of Agricultural Sciences (CXGC2016A01).

\section{Availability of data and materials}

All data generated or analysed during this study are included in this published article and its supplementary information files.

\section{Ethics approval and consent to participate}

Not applicable.

\section{Consent for publication}

Not applicable.

\section{Competing interests}

The authors declare that they have no competing interests.

\section{Received: 26 February 2020 Accepted: 24 September 2020}

Published online: 02 October 2020

\section{References}

1. Bertioli DJ, Cannon SB, Froenicke L, Huang G, Farmer AD, Cannon EK, et al. The genome sequences of Arachis duranensis and Arachis ipaensis, the diploid ancestors of cultivated peanut. Nat Genet. 2016;48(4):438-46.

2. Vahdati $\mathrm{K}$, Lotfi N. Abiotic stress tolerance in plants with emphasizing on drought and salinity stresses in walnut. In: Vahdati K, Leslie C, editors. Abiotic stress-plant responses and applications in agriculture. Rijeka: InTech; 2013. p. 307-65.

3. Arab MM, Marrano A, Abdollahi-Arpanahi R, Leslie CA, Cheng H, Neale DB, Vahdati K. Combining phenotype, genotype and environment to uncover genetic components underlying water use efficiency in Persian walnut. J Exp Bot. 2020;71(3):1107-27.

4. Zhu J. Abiotic stress signaling and responses in plants. Cell. 2016;167(2):31324.
5. Qu L, Zhu YX. Transcription factor families in Arabidopsis: major progress and outstanding issues for future research. Curr Opin Plant Biol. 2006;9(5): 544-9.

6. Nakashima K, Tran LS, Van ND, Fujita M, Maruyama K, Todaka D, Ito Y, Hayashi N, Shinozaki K, Yamaguchi-Shinozaki K. Functional analysis of a NAC-type transcription factor OsNAC6 involved in abiotic and biotic stressresponsive gene expression in rice. Plant J. 2007;51(4):617-30.

7. Hussain RM, Ali M, Feng X, Li X. The essence of NAC gene family to the cultivation of drought-resistant soybean (Glycinemax L. Merr.) cultivars. BMC Plant Biol. 2017;17(1):55.

8. Tran LS, Nakashima K, Sakuma Y, Simpson SD, Fujita Y, Maruyama K, Fujita M, Seki M, Shinozaki K, Yamaguchi-Shinozaki K. Isolation and functional analysis of Arabidopsis stress-inducible NAC transcription factors that bind to a drought-responsive cis-element in the early responsive to dehydration stress 1 promoter. Plant Cell. 2004;16(9):2481-98.

9. Xu B, Ohtani M, Yamaguchi M, Toyooka K, Wakazaki M, Sato M, Kubo M. Contribution of NAC transcription factors to plant adaptation to land. Science. 2014;343(6178):1505-8.

10. Hu R, Qi G, Kong Y, Kong D, Gao Q, Zhou G. Comprehensive analysis of NAC domain transcription factor gene family in Populus trichocarpa. BMC Plant Biol. 2010;10:145

11. Karanja BK, Xu L, Wang Y, Muleke EM, Jabir BM, Xie Y, Zhu X, Cheng W, Liu L. Genome-wide characterization and expression profiling of NAC transcription factor genes under abiotic stresses in radish (Raphanus sativus L.). Peer J. 2017;5:e4172.

12. Zhuo X, Zheng T, Zhang Z, Zhang Y, Jiang L, Ahmad S, Sun L, Wang J, Cheng T, Zhang Q. Genome-wide analysis of the NAC transcription factor gene family reveals differential expression patterns and cold-stress responses in the Woody Plant Prunusmume. Genes. 2018;9(10):494.

13. Guérin C, Roche J, Allard V, Ravel C, Mouzeyar S, Bouzidi MF. Genome-wide analysis, expansion and expression of the NAC family under drought and heat stresses in bread wheat (T. aestivum L.). PLoS One. 2019;14(3):e0213390.

14. Sun H, Hu M, Li J, Chen L, Li M, Zhang S, Zhang X, Yang X. Comprehensive analysis of NAC transcription factors uncovers their roles during fiber development and stress response in cotton. BMC Plant Biol. 2018;18(1):150.

15. Diao W, Snyder JC, Wang S, Liu J, Pan B, Guo G, Ge W, Dawood MH. Genome-wide analyses of the NAC transcription factor gene family in pepper (Capsicum annuum L.): chromosome location, phylogeny, structure, expression patterns, cis-elements in the promoter, and interaction network. Int J Mol Sci. 2018;19:1028.

16. Shen S, Zhang Q, Shi Y, Sun Z, Zhang Q, Hou S, Wu R, Jiang L, Zhao X, Guo $Y$. Genome-wide analysis of the NAC domain transcription factor gene family in Theobroma cacao. Genes. 2020;11:35.

17. Pascual M, Belen C, Francisco M, Concepcion A. The NAC transcription factor family in maritime pine (Pinus Pinaster): molecular regulation of two genes involved in stress responses. BMC Plant Biol. 2015;15(1):254.

18. Chakraborty R, Roy S. Evaluation of the diversity and phylogenetic implications of NAC transcription factor members of four reference species from the different embryophytic plant groups. Physiol Mol Biol Plants. 2019; 25:347-59.

19. Pascual MB, Llebres MT, Craven-Bartle B, Canas RA, Canovas FM, Avila C $P p N A C 1$, a main regulator of phenylalanine biosynthesis and utilization in maritime pine. Plant Biotechnol J. 2017:16(5):1094-104.

20. Zhang X, Cheng Z, Zhao K, Yao W, Sun X, Jiang T, Zhou B. Functional characterization of poplar NAC13 gene in salt tolerance. Plant Sci. 2019;281: $1-8$.

21. Perochon A, Kahla A, Vranić M, Jia J, Malla KB, Craze M, Wallington E, Doohan FM. A wheat NAC interacts with an orphan protein and enhances resistance to Fusarium head blight disease. Plant Biotechnol J. 2019;17(10): 1892-904.

22. Wang B, Wei J, Song N, Wang N, Zhao J, Kang Z. A novel wheat NAC transcription factor, TaNAC30, negatively regulates resistance of wheat to stripe rust. J Integr Plant Biol. 2018;60(5):432-43.

23. Xu Z, Wang $C$, Xue F, Zhang $H$, Ji W. Wheat NAC transcription factor TaNAC29 is involved in response to salt stress. Plant Physiol Biochem. 2015; 96:356-63.

24. Liu C, Wang B, Li Z, Peng Z, Zhang J. TsNac is a key transcription factor in abiotic stress resistance and growth. Plant Physiol. 2018;176(1):742-56

25. Wang G, Zhang S, Ma X, Wang Y, Kong F, Meng Q. A stress-associated NAC transcription factor (SINAC35) from tomato plays a positive role in biotic and abiotic stresses. Physiol Plant. 2016;158(1):45-64. 
26. Hu H, Dai M, Yao J, Xiao B, Li X, Zhang Q, Xiong L. Overexpressing a NAM, ATAF, and CUC (NAC) transcription factor enhances drought resistance and salt tolerance in rice. Proc Natl Acad Sci. 2006;103(35):12987-92.

27. Liu X, Hong L, Li XY, Yao Y, Hu B, Li L. Improved drought and salt tolerance in transgenic Arabidopsis overexpressing a NAC transcriptional factor from Arachis hypogaea. Biosci Biotechnol Biochem. 2011;75(3):443-50.

28. Liu X, Liu S, Wu J, Zhang B, Li X, Yan Y, Li L. Overexpression of Arachis hypogaea NAC3 in tobacco enhances dehydration and drought tolerance by increasing superoxide scavenging. Plant Physiol Biochem. 2013;70:354-9.

29. Tang GY, Shao FX, Xu PL, Shan L, Liu Z. Overexpression of a peanut NAC gene, AhNAC4, confers enhanced drought tolerance in tobacco. Russ J Plant Physol. 2017;64(4):525-35.

30. Pandurangaiah $\mathrm{M}$, Lokanadha $\mathrm{RG}$, Sudhakarbabu O, Nareshkumar A, Kiranmai K, Lokesh U, Thapa G, Sudhakar C. Overexpression of horsegram (Macrotyloma uniflorum Lam.Verdc.) NAC transcriptional factor (MuNAC4) in groundnut confers enhanced drought tolerance. Mol Biotechnol. 2014;56(8): 758-69.

31. Chen X, Lu Q, Liu H, Zhang J, Hong Y, Lan H, et al. Sequencing of cultivated peanut, Arachis hypogaea, yields insights into genome evolution and oil improvement. Mol Plant. 2019:1-15.

32. Zhuang W, Chen H, Yang M, Wang J, Pandey MK, Zhang C, et al. The genome of cultivated peanut provides insight into legume karyotypes, polyploid evolution and crop domestication. Nat Genet. 2019;51(5):865-76.

33. Chen X, Li H, Pandey MK, Yang Q, Wang X, Garg V, et al. Draft genome of the peanut A-genome progenitor (Arachis duranensis) provides insights into geocarpy, oil biosynthesis, and allergens. Proc Natl Acad Sci. 2016;113(24): 6785-90.

34. Yin D, Ji C, Ma X, Li H, Zhang W, Li S, Liu F, Zhao K, Li F, Li K, Ning L, He J, Wang $Y$, Zhao F, Xie $Y$, Zheng H, Zhang $X$, Zhang $Y$, Zhang J. Genome of an allotetraploid wild peanut Arachis monticola: a de novo assembly. Gigascience. 2018;7(6):giy066.

35. Bertioli DJ, Jenkins J, Clevenger J, Dudchenko O, Gao D, Seijo G, et al. The genome sequence of segmental allotetraploid peanut Arachis hypogaea. Nat Genet. 2019;51(5):877-84.

36. Clevenger J, Chu Y, Scheffler B, Oziasakins PA. Developmental Transcriptome map for Allotetraploid Arachis hypogaea. Front Plant Sci. 2016:7:1446.

37. Zhao X, Li C, Wan S, Zhang T, Yan C, Shan S. Transcriptomic analysis and discovery of genes in the response of Arachis hypogaea to drought stress. Mol Biol Rep. 2018;45(2):119-31.

38. Wang H, Lei Y, Wan L, Yan L, LV J, Dai X, Ren X, Guo W, Jiang H, Liao B. Comparative transcript profiling of resistant and susceptible peanut postharvest seeds in response to aflatoxin production by Aspergillus flavus. BMC Plant Biol. 2016;16:54.

39. Zhang H, Zhao XB, Sun QX, Yan CX, Wang J, Yuan CL, Li CJ, Shan SH, Liu FZ. Comparative transcriptome analysis reveals molecular defensive mechanism of Arachis hypogaea in response to salt stress. Int J Genomics. 2020;13.

40. Ooka H, Satoh K, Doi K, Nagata T, Otomo Y, Murakami K, Matsubara K, Osato N, Kawai J, Carninci P, Hayashizaki Y, Suzuki K, Kojima K, Takahara Y, Yamamoto K, Kikuchi S. Comprehensive analysis of NAC family genes in Oryza sativa and Arabidopsis thaliana. DNA Res. 2003;10(6):239-47.

41. Fang Y, You J, Xie K, Xie W, Xiong L. Systematic sequence analysis and identification of tissue-specific or stress-responsive genes of NAC transcription factor family in rice. Mol Gen Genomics. 2008;280(6):547-63.

42. Yan J, Wang B, Jiang Y, Cheng L, Wu T. GmFNSIl-controlled soybean flavone metabolism responds to abiotic stresses and regulates plant salt tolerance. Plant Cell Physiol. 2014;55(1):74-86.

43. Germain H, Lachance D, Pelletier G, Fossdal CG, Solheim H, Seguin A. The expression pattern of the Picea glauca Defensin 1 promoter is maintained in Arabidopsis thaliana, indicating the conservation of signalling pathways between angiosperms and gymnosperms. J Exp Bot. 2012;63(2):785-95.

44. Mark R, Olive JC, Walker KS, Elizabeth SD, James P. Functional properties of the anaerobic responsive element of the maize Adh1 gene. Plant Mol Biol. 1990;15(4):593-604.

45. Liu Z, Fu M, Li H, Chen Y, Wang L, Liu R. Systematic analysis of NAC transcription factors in Gossypium barbadense uncovers their roles in response to Verticillium wilt. Peer J. 2019;7:e7995.

46. Pinheiro GL, Marques CS, Costa MD, Reis PA, Alves MS, Carvalho CM, Fietto $L G$, Fontes EP. Complete inventory of soybean NAC transcription factors: sequence conservation and expression analysis uncover their distinct roles in stress response. Gene. 2009:444(1-2):10-23.
47. Yuan $\mathrm{CL}$, Sun QX, Kong YZ. Genome-wide mining seed-specific candidate genes from peanut for promoter cloning. PLoS One. 2019;14(3):e0214025.

48. Chien VH, Tien LD, Rie N, Yasuko W, Saad S, Uyen TT, Keiichi M, Nguyen VD, Kazuko Y, Kazuo S, Lam-Son PT. The auxin response factor transcription factor family in soybean: genome-wide identification and expression analyses during development and water stress. DNA Res. 2013;20(5):511-24.

49. Song H, Wang PF, Lin J, Zhao CZ, Bi YP, Wang XJ. Genome-wide identification and characterization of WRKY gene family in peanut. Front Plant Sci. 2016;7:534.

50. Altenhoff AM, Dessimoz C. Inferring orthology and paralogy. Methods Mol Biol. 2012:855:259-79.

51. Song H, Wang PF, Hou L, Zhao SZ, Zhao CZ, Xia H, Li PC, Zhang Y, Bian XT, Wang XJ. Global analysis of WRKY genes and their response to dehydration and salt stress in soybean. Front Plant Sci. 2016;7:9.

52. He X, Mu R, Cao W, Zhang Z, Zhang J, Chen S. AtNAC2, a transcription factor downstream of ethylene and auxin signaling pathways, is involved in salt stress response and lateral root development. Plant J. 2005:44:903-16.

53. Liu Y, Sun J, Wu Y. Arabidopsis ATAF1 enhances the tolerance to salt stress and $A B A$ in transgenic rice. J Plant Res. 2016;129:955-62.

54. Higo K, Ugawa Y, Iwamoto M, Korenaga T. Plant cis-acting regulatory DNA elements (PLACE) database: 1999. Nucleic Acids Res. 1999;27(1):297-300.

55. Deng W, Wang Y, Liu Z, Cheng H, Xue Y. Heml: a toolkit for illustrating heatmaps. PLoS One. 2014;9(11):e111988.

56. Rao $X$, Huang $X$, Zhou $Z$, Lin $X$. An improvement of the $2^{-\Delta \Delta C T}$ method for quantitative real-time polymerase chain reaction data analysis. Biostat Bioinforma Biomath. 2013;3(3):71-85.

\section{Publisher's Note}

Springer Nature remains neutral with regard to jurisdictional claims in published maps and institutional affiliations.

\section{Ready to submit your research? Choose BMC and benefit from:}

- fast, convenient online submission

- thorough peer review by experienced researchers in your field

- rapid publication on acceptance

- support for research data, including large and complex data types

- gold Open Access which fosters wider collaboration and increased citations

- maximum visibility for your research: over $100 \mathrm{M}$ website views per year

At BMC, research is always in progress.

Learn more biomedcentral.com/submissions 